\title{
Promoção de crescimento e solubilização de fosfato na cultura da soja: coinoculação de sementes com Bradyrhizobium japonicum e Pseudomonas fluorescens
}

\author{
Growth promotion and phosphate solubilization in soybean crop: seed coinoculation with
} Bradyrhizobium japonicum and Pseudomonas fluorescens

Promoción del crecimiento y solubilización de fosfatos en cultivos de soja: coinoculación de semillas con Bradyrhizobium japonicum y Pseudomonas fluorescens

Vandeir Francisco Guimarães

ORCID: https://orcid.org/0000-0000-7117-1905 Universidade Estadual do Oeste do Paraná, Brasil E-mail: vandeirfg@yahoo.com.br Jeferson Klein

ORCID: https://orcid.org/0000-0002-2075-362X Biogenesis Centro de Pesquisa e Desenvolvimento Ltda, Brasil E-mail: jefersonklein@yahoo.com.br

Débora Kestring Klein

ORCID: https://orcid.org/0000-0002-5443-642X Biogenesis Centro de Pesquisa e Desenvolvimento Ltda, Brasil E-mail: deborakestring@yahoo.com.br

\begin{abstract}
Resumo
Pesquisas com inoculantes contendo bactérias com capacidade de fixação biológica de nitrogênio, bem como promoção de crescimento, principalmente associada ao crescimento radicular já são bem conhecidas e consolidadas para a cultura da soja. Estudos que visam a promoção de crescimento vegetal com foco na solubilização do fosfato no solo são mais recentes e promissores, visto a importância e a difícil dinâmica deste nutriente no solo. Desta forma, o presente estudo teve por objetivo avaliar o potencial a campo, da promoção de crescimento e solubilização de fosfato, de inoculante líquido contendo isolados de Pseudomonas fluorescens, Cepa ATCC 13525, para a cultura da soja, via tratamento de sementes, associado à adubação fosfatada. Conduziu-se quatro ensaios, de outubro de 2018 a março de 2019 em áreas experimentais localizadas nos municípios de Toledo, Palotina, São Miguel do Iguaçu e Cascavel, no estado do Paraná. Utilizou-se delineamento de blocos casualizados, com sete tratamentos e quatro repetições, totalizando 28 parcelas experimentais em cada experimento. Os tratamentos foram: T1- Controle (sem adubação fosfatada e sem inoculação das sementes); T2- 50\% de adubação fosfatada (super triplo) e sem inoculação; T3- 100\% de adubação fosfatada e sem inoculação; T4- 50\% de adubação fosfatada e inoculação das sementes com o inoculante a base de $P$. fluorescens, na dose de $50 \mathrm{~mL} 50 \mathrm{~kg}^{-1}$ de sementes; T5- 50\% de adubação fosfatada e inoculação das sementes com $P$. fluorescens (100 mL50 kg-1 de sementes); T6- 50\% de adubação fosfatada e inoculação das sementes com $P$. fluorescens (150 mL50 kg-1 de sementes); T7- 50\% de adubação fosfatada e inoculação das sementes com $P$. fluorescens (200 mL50 kg-1 de sementes). Todos os tratamentos foram também inoculados com Bradyrhizobium japonicum (estirpes 5079 e 5080), na dose de $100 \mathrm{~mL} 50 \mathrm{~kg}^{-1}$ de sementes.
\end{abstract}

Palavras-chave: Glycine max L.; Bactérias promotoras de crescimento vegetal; Bactérias solubilizadoras de fosfato; Inoculação de sementes e produtividade.

\begin{abstract}
Research with inoculants containing bacteria with biological nitrogen fixation capacity, as well as growth promotion, mainly associated with root growth are already well known and consolidated for the soybean crop. Studies aimed at promoting plant growth with a focus on phosphate solubilization in the soil are more recent and promising, given the importance and difficult dynamics of this nutrient in the soil. Thus, the present study aimed to evaluate the field potential of promoting growth and phosphate solubilization of a liquid inoculant containing Pseudomonas fluorescens isolates, Strain ATCC 13525, for soybean cultivation, via seed treatment, associated with phosphate fertilization. Four trials were conducted, from October 2018 to March 2019 in experimental areas located in the municipalities of Toledo, Palotina, São Miguel do Iguaçu and Cascavel, in the state of Paraná. A randomized block design was used, with seven treatments and four replications, totaling 28 experimental plots in each experiment. The treatments were: T1- Control (without phosphate fertilization and without seed inoculation); T2- 50\% phosphate fertilization (super triple) and no inoculation; T3- 100\% phosphate fertilization and no inoculation; T4- 50\% phosphate fertilization and
\end{abstract}


inoculation of seeds with the inoculant based on P. fluorescens, at a dose of $50 \mathrm{~mL} 50 \mathrm{~kg}-1$ of seeds; T5- 50\% phosphate fertilization and seed inoculation with $P$. fluorescens (100 mL50 kg-1 of seeds); T6- 50\% phosphate fertilization and seed inoculation with $P$. fluorescens $(150 \mathrm{~mL} 50 \mathrm{~kg}-1$ of seeds); T7- $50 \%$ phosphate fertilization and seed inoculation with $P$. fluorescens (200 mL50 kg-1 of seeds). All treatments were also inoculated with Bradyrhizobium japonicum (strains 5079 and 5080), at a dose of $100 \mathrm{~mL} 50 \mathrm{~kg}-1$ of seeds.

Keywords: Glycine max L.; Plant growth promoting bacteria; Phosphate solubilizing bacteria; Seed inoculation e productivity.

\begin{abstract}
Resumen
La investigación con inoculantes que contienen bacterias con capacidad biológica de fijación de nitrógeno, así como la promoción del crecimiento, principalmente asociada al crecimiento radicular, ya son bien conocidas y consolidadas para el cultivo de la soja. Los estudios dirigidos a promover el crecimiento de las plantas con un enfoque en la solubilización de fosfato en el suelo son más recientes y prometedores, dada la importancia y la difícil dinámica de este nutriente en el suelo. Así, el presente estudio tuvo como objetivo evaluar el potencial de campo para promover el crecimiento y la solubilización de fosfato de un inoculante líquido que contiene aislados de Pseudomonas fluorescens, Cepa ATCC 13525, para el cultivo de soja, vía tratamiento de semillas, asociado a fertilización con fosfato. Se realizaron cuatro ensayos, de octubre de 2018 a marzo de 2019 en áreas experimentales ubicadas en los municipios de Toledo, Palotina, São Miguel do Iguaçu y Cascavel, en el estado de Paraná. Se utilizó un diseño de bloques al azar, con siete tratamientos y cuatro repeticiones, totalizando 28 parcelas experimentales en cada experimento. Los tratamientos fueron: T1- Control (sin fertilización fosfatada y sin inoculación de semillas); T2- Fertilización con fosfato al 50\% (super triple) y sin inoculación; T3- Fertilización con fosfato al 100\% y sin inoculación; T4Fertilización con fosfato al $50 \%$ e inoculación de semillas con el inoculante a base de $P$. fluorescens, a una dosis de 50 mL 50 kg-1 de semillas; T5- Fertilización con fosfato al 50\% e inoculación de semillas con P. fluorescens (100 mL 50 kg-1 de semillas); T6- Fertilización con fosfato al 50\% e inoculación de semillas con P. fluorescens (150 mL $50 \mathrm{~kg}-1$ de semillas); T7- Fertilización con fosfato al 50\% e inoculación de semillas con P. fluorescens (200 mL $50 \mathrm{~kg}-1 \mathrm{de}$ semillas). Todos los tratamientos también fueron inoculados con Bradyrhizobium japonicum (cepas 5079 y 5080), a una dosis de $100 \mathrm{~mL} 50 \mathrm{~kg}-1$ de semillas.
\end{abstract}

Palabras clave: Glicina max. L.; Bacterias promotoras del crecimiento de las plantas; Bacterias solubilizadoras de fosfato; Inoculación y rendimiento de semillas.

\title{
1. Introdução
}

A soja (Glycine max (L.) Merr.) pertence à família Fabaceae, com enorme importância mundial. Seu destaque econômico deve-se ao alto valor nutricional e baixo custo de produção quando comparado a outras culturas de grande importância econômica. É principalmente utilizada como fonte primaria de óleo e proteína vegetal. Seus grãos, apresentam alto teor de proteína (40\%) e lipídeos, podendo estes dois componentes, representar 60\% do peso de grãos (Moraes et al., 2006). Atualmente é um dos principais produtos utilizados e comercializados, devido sua ampla utilização, seja na alimentação humana, óleo comestível e ração animal, além de fazer parte da composição de vários produtos alimentícios industrializados (Mandarino \& Carrao-Panizzi, 2008), bem como produção de biocombustíveis (Yokomizo et al., 2000).

Atualmente, o Brasil é o segundo maior produtor mundial e o maior da América Latina. A produção nacional da soja abrange todas as regiões do país, concentrando-se nas regiões Centro-Oeste e Sul, com 45 e 35\%, respectivamente, da área correspondente à cultura. Juntas essas regiões respondem por $80 \%$ da produção nacional de grãos de soja. Os Estados de Mato Grosso, Paraná, Rio Grande do Sul e Goiás são responsáveis por 71,7\% da produção nacional. Na safra 2018/2019 foram produzidas no país, 114,8 milhões de toneladas de grãos de soja, em uma área de aproximadamente 36 milhões de hectares, da qual, o Paraná foi responsável por cerca de 14\% da produção em uma área de 5,4 milhões de hectares (CONAB, 2019).

Por ser uma leguminosa de grande valor nutritivo, possuindo aproximadamente $40 \%$ de proteína, apresenta grande exigência de nutrição mineral. Esta demanda se dá principalmente por nitrogênio $(\mathrm{N})$, sendo necessária aproximadamente 80 $\mathrm{kg} \mathrm{ha}^{-1}$ para cada $1 \mathrm{t}$ de grãos produzidos (Hungria et al., 2001). Conforme Andrade et al., (2009), em virtude desta elevada demanda de nutrientes via adubação, tem-se relatado grandes impactos ambientais.

Os avanços científicos e a disponibilização de tecnologias ao setor produtivo proporcionaram alcançar elevada produtividade na cultura de soja. A utilização do processo de fixação biológica de nitrogênio (FBN), com estirpes eficientes, 
associadas à seleção de cultivares responsivas às interações planta-microrganismos, tem resultado em dispensa ou minimização da necessidade de fertilização nitrogenada. Aliado a essa tecnologia, tem-se avançado as pesquisas bem como a utilização da prática da coinoculação, que combina uma prática já bem conhecida dos produtores (a inoculação das sementes de soja com Bradyrhizobium), com a inoculação de bactérias promotoras de crescimento vegetal (BPCV) (Nogueira et al., 2018).

Neste contexto, resultados científicos têm apontado para a eficiência agronômica desta técnica. Como exemplo podese citar o estudo de Braccini et al. (2016) relatam que a inoculação via tratamento de sementes e a utilização da associação do Bradyrhizobium japonicum com Azospirillum brasilense, via sulco de semeadura, proporcionou incrementos nos caracteres fisiológicos, bem como promoveu acréscimos no rendimento de grãos da soja, quando comparado com a testemunha. Estes autores relatam ainda que a introdução de bactérias via sementes, portanto, apresenta-se como uma opção ideal, devido ao menor custo para o produtor rural. Estes microrganismos têm reconhecido papel por estímulos hormonais vegetais (auxinas, ácido giberélico, citocininas, ácido abscísico e poliaminas). Dentre outros efeitos benéficos via interação bactéria-planta (Bárbaro et al., 2009; Figueiredo et al., 2010; Araújo et al., 2012). Estas respostas se expressam em potencialização da nodulação e maior crescimento radicular em resposta à interação positiva entre essas bactérias (Bárbaro et al. (2011).

Além do nitrogênio, outro macronutriente muito importante para os vegetais é o fósforo. Este apresenta dinâmica bem distinta no solo. Desta forma, tem-se constatado a aplicação de fertilizantes fosfatados com objetivo de suprir a deficiência de P. Porém, quando fontes solúveis de P são adicionadas ao solo, esse elemento pode ser adsorvido na superfície dos colóides ou convertido a compostos muito pouco solúveis de Fe e $\mathrm{Al}$ (Brady \& Weil, 1996). Isso contribui para o baixo nível de eficiência (10\% a $25 \%)$ dos adubos fosfatados aplicado ao solo. Para superar esses problemas, doses relativamente elevadas de fertilizantes são necessárias para a obtenção de produções econômicas.

Neste contexto pode-se considerar outro efeito promotor de crescimento que vem sendo estudado, a solubilização de fosfato por microrganismos que inoculados, via semente ou suco de semeadura. Estes microrganismos podem favorecer o crescimento e desenvolvimento das plantas. Existem relatos na literatura de várias BPCV que têm capacidade de produzir enzimas (fosfatases ácidas) que agem disponibilizando o $\mathrm{P}$ ligado à matéria orgânica e ácidos orgânicos que podem agir disponibilizando o P pouco solúvel ligado a compostos de Fe e Al. (Bolan et al., 1997).

Esta técnica visa o melhor aproveitamento de fosfatos insolúveis, a inoculação com Rizobactérias Promotoras de Crescimento de Plantas (RPCPs) é uma opção para a promoção de crescimento e da solubilização de fosfatos inorgânicos, mediante excreção de ácidos orgânicos e colonização rizosférica (Bolan et al., 1997). A interação entre microrganismos e fontes de $\mathrm{P}$ é também uma forma de reduzir custos. Os microrganismos podem ser usados na forma de inoculantes visando o aumento da disponibilidade de P para as plantas, por meio da solubilização e mineralização do P de fontes inorgânicas e orgânicas, respectivamente (Richardson, 2001). O principal efeito da solubilização de fosfato na promoção de crescimento de plantas está no aumento da biomassa e no teor de P das plantas (Bashan et al., 2004).

Além de favorecer a solubilização dos fosfatos naturais, as rizobactérias podem aumentar a eficiência das fontes solúveis. Estas bactérias também possuem a capacidade de promover o crescimento radicular, permitindo assim maior exploração do solo e absorção de P, proporcionando maior intercepção radicular. Assim, o uso de rizobactérias promotoras do crescimento como inoculantes biológicos constitui uma alternativa para a produção sustentável, sendo uma tecnologia com potencial para melhorar a produtividade dos sistemas agrícolas, a longo prazo (Hungria et al., 2001; Naiman et al., 2009).

Estudos têm apontado para o potencial de solubilização de fosfatos por BPCV dos gêneros Pseudomonas e Bacillus, bem como por alguns fungos associativos como é o caso das Micorrizas, Aspergillus, etc. (Souchie et al., 2005; Chaves et al., 2013; Sousa et al., 2016).

Diante dos resultados de pesquisa e dos avanços tecnológicos de produção de inoculantes para coinoculação com bactérias fixadoras de nitrogênio, a busca de microrganismo com potencial para a promoção de crescimento, com enfoque na 
solubilização de fosfatos é uma nova realidade a ser explorada, principalmente para o cultivo em Latossolos, o qual têm a característica de grande imobilização de $\mathrm{P}$, reduzindo bastante a eficiência de absorção deste nutriente pelas plantas.

Neste sentido, baseando-se na contextualização já apresentada, objetivou-se com o presente estudo avaliar o potencial de promoção de crescimento e solubilização de fosfato mediante coinoculação, via sementes, de Bradyrhizobium japonicum e Pseudomonas fluorescens na cultura da soja.

\section{Metodologia}

\section{Localização de caracterização das áreas experimentais}

O estudo foi conduzido em quatro localidades, no período de outubro de 2018 a abril de 2019, nos municípios de Toledo, Latitude de 2440'13.38” S e Longitude 53³9’49.36” O, em LATOSSOLO VERMELHO distroférrico típico de textura muito argilosa; Palotina, Latitude de 24¹6’31.37” S e Longitude 5343'44.09” O, em LATOSSOLO VERMELHO eutroférrico de textura muito argilosa; São Miguel do Iguaçu, Latitude de 25²3’08.52” S e Longitude 54¹2’44.99” O, em NITOSSOLO VERMELHO eutroférrico de textura muito argilosa; e Cascavel, Latitude de $25^{\circ} 04^{\prime} 15.65^{\prime}$ S e Longitude 533' 46.70” O, em LATOSSOLO VERMELHO eutroférrico de textura muito argilosa todas no estado do Paraná.

As caracterizações químicas e físicas dos solos das áreas experimentais foram realizadas através da análise de material, proveniente de amostras compostas por dez subamostras em cada área experimental, na profundidade de 0 a 0,20 m. Os resultados são apresentados na Tabela 1. 
Tabela 1. Características químicas e granulométricas do solo da área experimental do município de Toledo - PR, Palotina - PR, São Miguel do Iguaçu - PR e Santa Tereza do Oeste - PR, 2018.

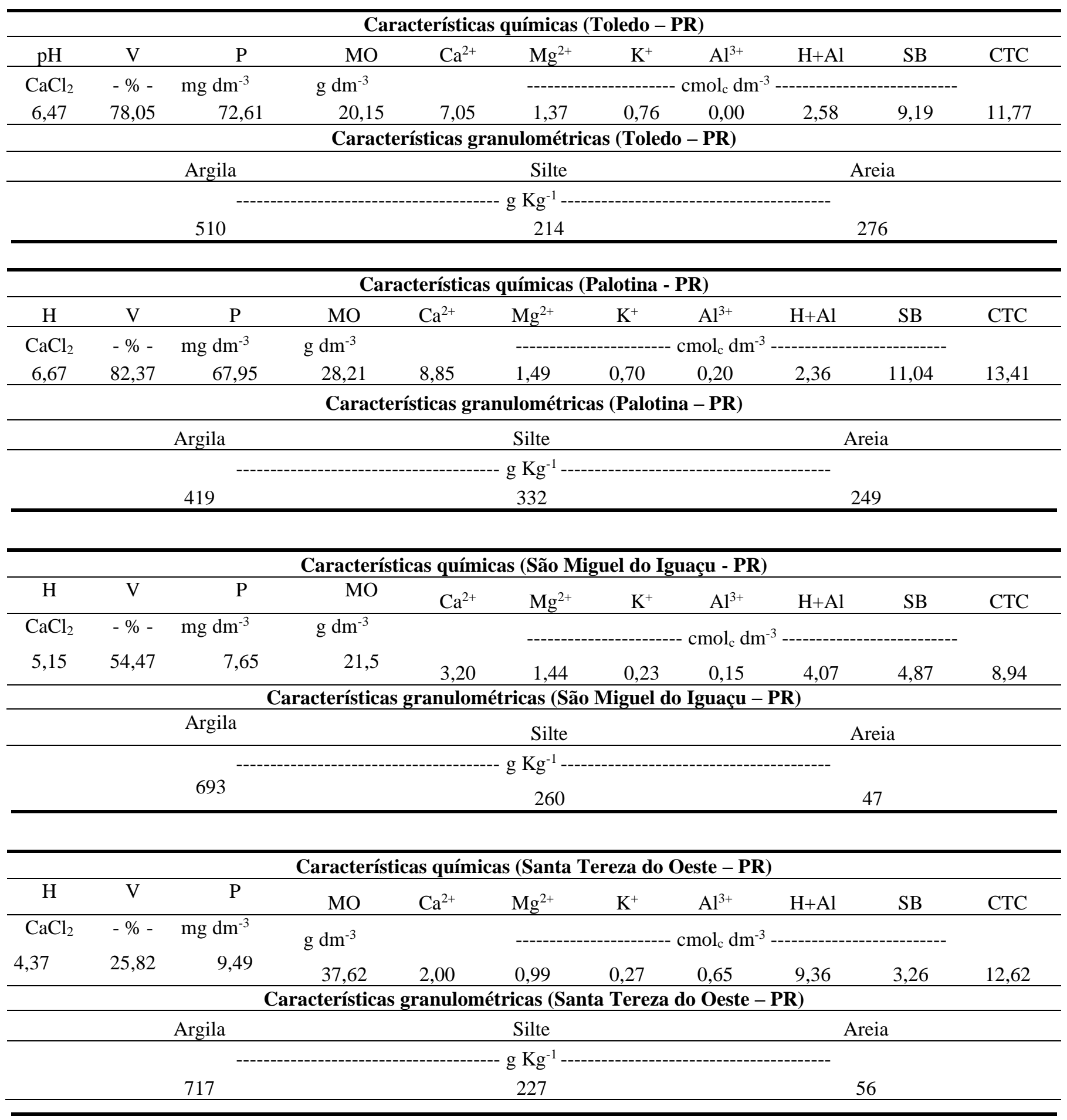

(P, K, Micronutrientes) Extrator Mehlich-1;(Al, Ca, Mg) Extrator $\mathrm{KCl} 1 \mathrm{~mol} \mathrm{~L}{ }^{-1}$; (H+Al) pH SMP (7,5); (pH) Extrator CaCl 20,01 mol L-1. Análise realizada no Laboratório PrimorLab localizado na cidade de Assis Chateaubriand, PR. Fonte: Autores.

Os dados meteorológicos das quatro áreas experimentais durante a condução e avaliação dos experimentos são apresentados nas Figuras 1 A, B, C e D. 
Figura 1. Dados médios de pluviosidade, temperatura mínima (๑), temperatura média $(\mathbf{\bullet})$ e temperatura máxima $(\boldsymbol{\Lambda})$, das diferentes localidades: A) Toledo - PR; B) Palotina - PR; C) São Miguel do Iguaçu - PR e D) Santa Tereza do Oeste - PR, durante o período de outubro de 2018 a abril de 2019.
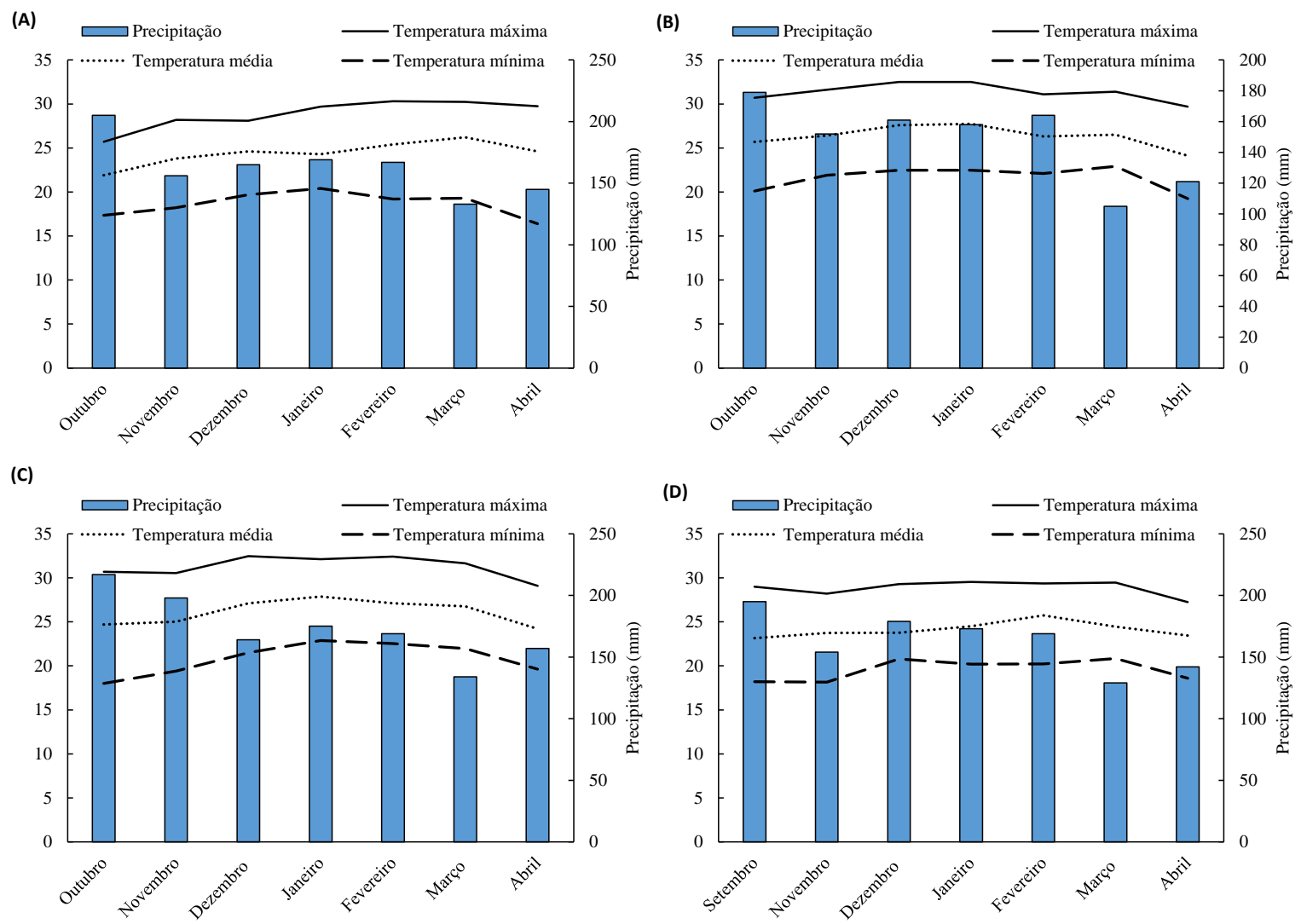

Fonte: Autores.

Em relação à correção destes solos, quando necessário, foi realizada 30 dias antes da semeadura, a elevação da saturação de bases para 70\% conforme EMBRAPA, (2011).

\section{Caracterização microbiológica dos solos e inoculantes utilizados nos ensaios}

A contagem de microrganismos diazotróficos para determinação da população de bactérias em $\mathrm{n}^{\circ}$ de células por $\mathrm{mL}$, foi realizada através da estimativa do Número Mais Provável (NMP) usando a tabela de MacCrady em meio semi-sólido NFB, de acordo com metodologia descrita por Döbereiner et al. (1995).

Os resultados da contagem de microrganismos diazotróficos nos solos dos experimentos, das quatro áreas experimentais, no momento da semeadura apresentavam população de: 2,4x $10^{5}$ (Toledo - PR); 1,5 x 106 (Palotina - PR); 2,5 x $10^{4}$ (São Miguel do Iguaçu - PR) e 1,8 x $10^{5}$ (Cascavel - PR), Unidade Formadoras de Colônias (UFC) g-1 de bactérias diazotróficas.

O inoculante utilizado nas quatro áreas experimentais, cedido pela empresa Fertibio Do Brasil Industria De Fertilizantes LTDA, apresentava as seguintes características: Garantia: 2,0x10 8 UFC/mL (Unidades Formadoras de Colônias) de Pseudomonas fluorescens, Cepa ATCC 13525, Natureza física: líquido; Cultura à que se destina: soja (Glycine max L.); Lote: 138249; Fabricação: 06/09/2018 e Validade: 06/10/2019. 


\section{Delineamento experimental, implantação e condução dos experimentos}

Os experimentos foram implantados em delineamento de blocos casualizados, com sete tratamentos e quatro repetições, totalizando 28 parcelas experimentais. Os tratamentos foram constituídos de T1- Controle (sem adubação fosfatada e sem inoculação das sementes); T2- 50\% de adubação fosfatada (super triplo) e sem inoculação; T3- 100\% de adubação fosfatada (super triplo) e sem inoculação; T4- 50\% de adubação fosfatada (super triplo) e inoculação das sementes com o inoculante a base de $P$. fluorescens , na dose de $50 \mathrm{~mL} 50 \mathrm{~kg}^{-1}$ de sementes; T5- 50\% de adubação fosfatada (super triplo) e inoculação das sementes com o inoculante a base de $P$. fluorescens, na dose de $100 \mathrm{~mL} 50 \mathrm{~kg}^{-1} \mathrm{de}^{-}$sementes; T6- 50\% de adubação fosfatada (super triplo) e inoculação das sementes com o inoculante a base de P. fluorescens, na dose de 150 mL50 $\mathrm{kg}^{-1}$ de sementes; T7- $50 \%$ de adubação fosfatada (super triplo) e inoculação das sementes com o inoculante a base de $P$. fluorescens, na dose de $200 \mathrm{~mL} 50 \mathrm{~kg}^{-1}$ de sementes. Todos os tratamentos foram inoculados com Bradyrhizobium japonicum

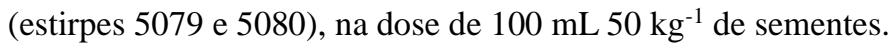

Anteriormente à semeadura, as sementes foram tratadas utilizando-se o fungicida Metalaxil - M + Fludioxonil (produto comercial Maxim XL®) na dose de $100 \mathrm{~mL}$ de p.c. para $100 \mathrm{~kg}$ de sementes, ainda para prevenção de doenças nos estádios iniciais de desenvolvimento utilizou-se ainda o inseticida Fipronil, na dosagem de $200 \mathrm{~mL}$ de p. c. para $100 \mathrm{~kg}$ de sementes.

Neste momento foram coletados os restos culturais em 10 pontos de cada área experimental, nas quatro áreas experimentais, com auxílio de um quadrado de metal de $1,0 \mathrm{~m}^{2}$, as quais foram pesadas, secas em estufa a $65^{\circ} \mathrm{C}$ e enviadas para análise dos teores de N, P e K nas amostras. Os resultados de massa seca da palhada foram: 11,7; 10,6; 12,6 e 14,9 T ha ${ }^{-1}$, respectivamente, para as quatro áreas experimentais, nos municípios de Toledo/PR, Palotina/PR, São Miguel do Iguaçu/PR e Santa Tereza do Oeste/PR.

De posse dos resultados de massa seca da palhada e dos teores de N, na massa seca da palhada, foram efetuados os cálculos de acúmulo nutricional, visando determinar a quantidade de nutrientes (N, P e K) acrescida na área pela palhada de cultivos antecessores, cujos resultados foram de 18,7; 7,8 e 11,0 $\mathrm{kg} \mathrm{ha}^{-1}$ de N, P e K para a área experimental de Toledo/PR; 13,1, 12,5 e 19,8 kg ha-1 de N, P e K para a área experimental de Palotina/PR; 19,6, 21,8 e 27,5 kg ha ${ }^{-1}$ de N, P e K para a área experimental de São Miguel do Iguaçu/PR e 25,3, 15,5 e 31,9 kg ha ${ }^{-1}$ de N, P e K para a área experimental de Santa Tereza do Oeste/PR, respectivamente.

Conforme os resultados da análise química do solo e necessidades da cultura, foi realizada a fertilização de base. Considerando que as áreas apresentavam teores de argila acima de entre $50 \%$ a $60 \%$ e teores de $\mathrm{P}$ acima dos $12 \mathrm{mg} \mathrm{dm}^{3}$ (Tabela 1) foram assim classificados como bom e muito bom, necessitando de fertilização de $60 \mathrm{~kg} \mathrm{ha}^{-1}$ de $\mathrm{P}_{2} \mathrm{O}_{5}$, utilizando como fonte superfostato triplo. Para a fertilização com K, os solos encontravam-se classificados como muito bom, valores acima de $0,31 \mathrm{cmol}_{\mathrm{c}} \mathrm{dm}^{3}$, necessitando assim a adição de $40 \mathrm{~kg} \mathrm{ha}^{-1}$ de $\mathrm{K}_{2} \mathrm{O}$, tendo como fonte cloreto de potássio. Para a distribuição dos fertilizantes utilizou-se uma semeadora adubadora de precisão, equipada com sistema de rosca sem fim, onde nesse momento foi realizado simultaneamente o sulcamento da área experimental. A adubação de semeadura com $100 \%$ do $\mathrm{P}$ foi utilizada para o tratamento T3 e de $50 \%$ do P para os tratamentos T2, T4, T5, T6 e T7. Aplicou-se ainda na semeadura, $50 \%$ de K e $50 \%$ em cobertura, a lanço, no estádio V6.

A cultivar de soja utilizada nos quatro ensaios foi a NIDERA NA 5909 RG, com ciclo precoce de alta produtividade médio de 120 dias, pertencente ao grupo de maturação 5.9 Esta apresenta crescimento indeterminado.

Cada parcela experimental foi composta de 10 linhas de semeadura por 8 metros de comprimento, com espaçamento de $1 \mathrm{~m}$ entre as parcelas. Utilizou-se espaçamento entre linhas de $0,5 \mathrm{~m}$, com 10 plantas $\mathrm{m}^{-1}$, conforme especificação do cultivar, perfazendo uma densidade populacional média de 240.000 plantas ha $^{-1}$. A parcela experimental útil, considerada para avaliações foi constituída pelas 6 linhas centrais, desprezando-se $1 \mathrm{~m}$ em cada extremidade, resultando em área útil de $48 \mathrm{~m}^{2}$. 
Para a inoculação das sementes foram retiradas alíquotas de inoculantes segundo os cálculos recomendados para cada tratamento, por meio de uma micropipeta modelo Micronam com capacidade de até $10 \mathrm{~mL}$. Acondicionou-se então, 2,0 kg de sementes de soja em sacos de plástico de alta densidade, onde o inoculante foi depositado diretamente sobre a massa de sementes conforme os tratamentos. Em seguida, os sacos plásticos foram agitados por aproximadamente 1 minuto para uniformizar a distribuição do inoculante nas sementes. As sementes ficaram sobre a bancada, a sombra, durante 2 horas, para então ser realizada a semeadura.

Os quatro experimentos foram implantados com as seguintes datas de semeadura: Toledo/PR (17 de setembro de 2018), Palotina/PR (21 de setembro de 2018), São Miguel do Iguaçu/PR (15 de setembro de 2018) e Santa Tereza do Oeste/PR (22 de setembro de 2018).

Após a germinação as plantas foram monitoradas visando um adequado desenvolvimento até alcançarem o estádio $\mathrm{R}_{1}$, sendo necessário a aplicação de herbicida no estádio $\mathrm{V}_{4}$ da cultura, com a aplicação do Roundup WG (Glifosato 7925 g kg-1) na dose de $0,8 \mathrm{~kg}$ p. c. ha- ${ }^{-1}$.

A primeira aplicação dos tratamentos com fungicidas foi realizada no estádio $\mathrm{R}_{1}$ com Trifloxistrobina $\left(150 \mathrm{~g} \mathrm{~L}^{-1}\right)+$ Protioconazol (175 $\mathrm{g} \mathrm{L}^{-1}$ ), juntamente com os fungicidas foi realizada a aplicação do herbicida e o inseticida Nomolt (Teflubenzuron $150 \mathrm{~g} \mathrm{~L}^{-1}$ ) na dose de $0,1 \mathrm{~L}$ p. c. ha ${ }^{-1}$, visando o controle de lagartas desfolhadoras.

Quando as plantas atingiram o estágio $\mathrm{R}_{4}$ utilizou-se os fungicidas Azoxistrobina $\left(300 \mathrm{~g} \mathrm{~kg}^{-1}\right)+$ Benzovindiflupir (150 $\mathrm{g} \mathrm{kg}^{-1}$ ), e visto a presença de vagens fez-se necessário a aplicação de inseticidas para o controle de percevejos através dos

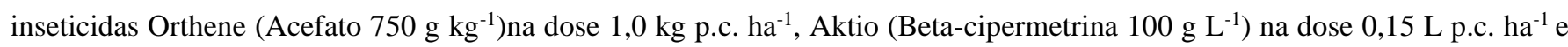
para o controle de lagartas desfolhadoras utilizou-se Belt (Flubendiaida $480 \mathrm{~g} \mathrm{~L}^{-1}$ ) na dose 0,1 L p.c. ha ${ }^{-1}$.

Uma última aplicação de fungicida foi realizada no estádio R5, com Epoxiconazol $\left(50 \mathrm{~g} \mathrm{~L}^{-1}\right)+$ Fluxapiroxade $(50 \mathrm{~g} \mathrm{~L}$

$\left.{ }^{1}\right)+$ Piraclostrobina $\left(81 \mathrm{~g} \mathrm{~L}^{-1}\right)$, nesse momento aplicou-se ainda os inseticidas para o controle de percevejo majoritariamente e lagartas desfolhadoras Engeo Pleno (Tiametoxam $141 \mathrm{~g} \mathrm{~L}^{-1}+$ lambda-cialotrina $106 \mathrm{~g} \mathrm{~L}^{-1}$ ) na dose 0,2 L p.c. ha-1, Lannate BR (Metomil $215 \mathrm{~g} \mathrm{~L}^{-1}$ )na dose 1,0 L p.c. ha-1 e Akito (Beta-cipermetrina $100 \mathrm{~g} \mathrm{~L}^{-1}$ ) na dose 0,1 L p.c. ha ${ }^{-1}$.

\section{Avaliação de variáveis morfobiométricas das plantas de soja}

No estádio fenológico $\mathrm{R}_{1}$ foram realizadas coletas de plantas para realização das avaliações de variáveis morfobiométricas das plantas. Para tanto foram coletadas 6 plantas, com raízes intactas, na segunda linha de cada parcela experimental.

As plantas foram acondicionadas em sacos plásticos e imediatamente levadas para laboratório para mensuração das seguintes variáveis: massa seca de raiz (MSR), número de nódulos por planta (NN), massa seca de nódulos (MSN), altura de planta (ALT) e diâmetro de caule (DC).

A altura das plantas e diâmetro do caule foi mensurada com régua graduada e paquímetro digital, respectivamente. A variáveis de massa seca dos diferentes órgãos foram obtidas por pesagem em balança de precisão, após a secagem dos materiais vegetais em estufa de circulação forçada de ar a $65^{\circ} \mathrm{C}$, até atingirem massa constante. Para a obtenção da massa seca de raízes e número e massa seca de nódulos, as raízes foram lavadas em água corrente com auxílio de peneiras para retirada do solo e recuperação dos nódulos para contagem e determinação da matéria seca.

Para a determinação do teor de nitrogênio, fósforo e potássio nas folhas, foram coletadas as folhas do terço superior das plantas de cada parcela útil. As folhas coletadas foram lavadas em água corrente e destilada e em seguida, acondicionadas em sacos de papel para a secagem em estufa de circulação forçada de ar, a $65{ }^{\circ} \mathrm{C}$ por $72 \mathrm{~h}$. Após a secagem as amostras foram moídas e submetidas à digestão sulfúrica e posteriormente a destilação por arraste de vapores de acordo com TEDESCO et al. (1995), determinando-se então o teor de nitrogênio foliar. 
No estádio fenológico R9, quando as plantas se encontravam com os grãos maduros, foram realizadas colheitas das parcelas úteis de cada tratamento para posterior determinação da produtividade. Para o cálculo da produtividade, a massa de grãos da parcela foi corrigida para $13 \%$ de umidade na base úmida e os valores extrapolados para $\mathrm{kg} \mathrm{ha}^{-1}$.

\section{Determinação do teor de N, P e K no tecido foliar e nos grãos}

Para os quatro ensaios, no estádio fenológico relativo à emissão da inflorescência feminina, foram coletadas as folhas da região oposta e abaixo da espiga principal de dez plantas de cada parcela útil. As folhas coletadas foram acondicionadas em sacos de papel Kraft e submetidas à secagem em estufa de circulação forçada de ar, a $65{ }^{\circ} \mathrm{C}$, até atingirem massa constante e armazenadas para posterior análise dos teores de N, P e K.

Após a colheita das espigas e debulha dos grãos, que será detalhada posteriormente, foram retiradas amostras de grãos correspondentes a cada parcela experimental. Estas amostras foram secas em estufa de circulação forçada de ar a $65^{\circ} \mathrm{C}$ até atingirem massa constante.

As amostras de folhas e grãos foram moídas e submetidas à digestão sulfúrica. Segundo a metodologia da Embrapa (2017) foi realizada a destilação por arraste de vapores, determinando-se então o teor de nitrogênio (N), fósforo (P) e potássio (K) nos tecidos que foram expressos em $\mathrm{g} \mathrm{kg}^{-1}$ de massa de matéria seca de folha e grão.

\section{Análise estatística dos dados}

Depois de serem tabulados, os dados foram submetidos à análise de variância pelo teste $\mathrm{F}(\mathrm{P} \leq 0,05)$ e as médias dos tratamentos foram comparadas pelo teste de Tukey $(\mathrm{P} \leq 0,05)$. Utilizou-se o software estatístico SISVAR, versão 5.3 (Ferreira, 2011).

\section{Resultados}

\section{Área experimental na cidade de Toledo/PR}

Ao avaliar os resultados obtidos para a área do município de Toledo verifica-se que todas as variáveis estudadas apresentaram efeitos significativos pelo teste $\mathrm{F}(\mathrm{p} \leq 0,01)$, com exceção para a variável número de nódulos por planta $\mathrm{NN}$, cuja variável analisada apresentou efeito significativo pelo teste $\mathrm{F}(\mathrm{p} \leq 0,05)$ (Tabela 2). 
Tabela 2. Massa seca de raiz (MSR), número de nódulos por planta (NN), massa seca de nódulos (MSN), altura de planta (ALT), diâmetro de caule (DC), massa seca total de parte aérea (MSTPA), teor de sob diferentes formas nitrogênio na folha (N foliar) e teor de nitrogênio nos grãos (N grãos) de plantas de soja NIDERA NA 5909 RG cultivadas com inoculação de sementes com P. fluorescens e fertilização fosfatada, Município de Toledo - PR.

\begin{tabular}{|c|c|c|c|c|c|c|}
\hline \multirow{2}{*}{ Trat. } & \multicolumn{2}{|l|}{ MSR } & \multirow{2}{*}{$\frac{\text { MSN }}{\text { mg planta }^{-1}}$} & \multirow{2}{*}{$\frac{\mathrm{ALT}}{\mathrm{Cm}}$} & \multirow{2}{*}{$\frac{\mathrm{DC}}{\mathrm{Mm}}$} & \multirow{2}{*}{$\frac{\text { MSF }}{\text { g planta }^{-1}}$} \\
\hline & g planta $^{-1}$ & ININ & & & & \\
\hline $\mathrm{T} 1$ & $0,60 \mathrm{~d}$ & $27,62 \mathrm{~b}$ & $116,77 \mathrm{~d}$ & $48,18 \mathrm{~b}$ & $42,25 \mathrm{c}$ & $12,65 \mathrm{~d}$ \\
\hline $\mathrm{T} 2$ & $1,26 \mathrm{~cd}$ & $29,53 \mathrm{ab}$ & $261,84 \mathrm{c}$ & $56,78 \mathrm{ab}$ & $68,75 \mathrm{~b}$ & $14,33 \mathrm{~cd}$ \\
\hline $\mathrm{T} 3$ & $2,44 \mathrm{a}$ & $32,46 \mathrm{ab}$ & 382,38 a & $61,13 \mathrm{a}$ & $105,50 \mathrm{a}$ & $19,19 \mathrm{a}$ \\
\hline $\mathrm{T} 4$ & $1,37 \mathrm{bcd}$ & $33,21 \mathrm{ab}$ & $324,25 \mathrm{~b}$ & $56,05 \mathrm{ab}$ & $74,25 \mathrm{~b}$ & $16,04 \mathrm{bc}$ \\
\hline T5 & $2,18 a b$ & $34,43 \mathrm{a}$ & $320,20 \mathrm{~b}$ & $61,00 \mathrm{a}$ & $79,78 \mathrm{~b}$ & $16,89 \mathrm{abc}$ \\
\hline T6 & $1,89 \mathrm{abc}$ & $32,86 \mathrm{ab}$ & $341,48 \mathrm{ab}$ & $56,53 \mathrm{a}$ & $68,68 \mathrm{~b}$ & $17,77 \mathrm{ab}$ \\
\hline $\mathrm{T} 7$ & $1,87 \mathrm{abc}$ & $32,96 \mathrm{ab}$ & $354,19 \mathrm{ab}$ & $62,55 \mathrm{a}$ & $80,25 \mathrm{~b}$ & $18,89 \mathrm{a}$ \\
\hline $\mathrm{CV}(\%)$ & 22,10 & 18,47 & 17,26 & 28,02 & 15,55 & 16,67 \\
\hline DMS & 0,86 & 6,31 & 50,94 & 10,96 & 25,29 & 2,58 \\
\hline F cal & $0,86 * *$ & $3,147 *$ & $66,638 * *$ & $5,168 * *$ & $121,63 * *$ & $18,915^{* *}$ \\
\hline
\end{tabular}

**significativo pelo teste $\mathrm{F}$ a $5 \%$ de probabilidade. Médias seguidas das mesmas letras minúsculas na coluna não diferem entre si pelo teste de Tukey a 5\% de probabilidade. Coeficiente de variação (CV (\%)); diferença mínima significativa (DMS). T1- Controle (sem adubação fosfatada e sem inoculação das sementes); T2- 50\% de adubação fosfatada (super triplo) e sem inoculação; T3- 100\% de adubação fosfatada (super triplo) e sem inoculação; T4- 50\% de adubação fosfatada (super triplo) e inoculação das sementes com o inoculante a base de $P$. fluorescens, na dose de $50 \mathrm{~mL} 50 \mathrm{~kg}^{-1}$ de sementes; T5- $50 \%$ de adubação fosfatada (super triplo) e inoculação das sementes com o inoculante a base de $P$. fluorescens, na dose de $100 \mathrm{~mL} 50 \mathrm{~kg}^{-1}$ de sementes; T6- $50 \%$ de adubação fosfatada (super triplo) e inoculação das sementes com o inoculante a base de $P$. fluorescens, na dose de $150 \mathrm{~mL}^{2} \mathrm{~kg}^{-1}$ de sementes; T7- 50\% de adubação fosfatada (super triplo) e

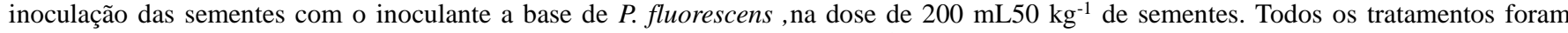

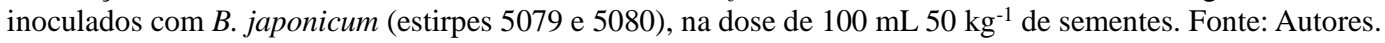

A massa seca de raiz (MSR), foi superior no tratamento T3, superando em 306,67\%, 93,65\% e 78,10 os tratamentos T1, T2 e T4, respectivamente (Tabela 2). Quando se analisa somente os tratamentos que receberam 50\% da adubação fosfatada para esta variável nota-se que os tratamentos que receberam a inoculação de $P$. fluorescens independentemente da dose T5, T6, T7 e T4 foram superiores ao tratamento T2 em 73,02\%, 50,00\%, 48,41\% e 08,73\% respectivamente (Tabela 2).

Para o número de nódulos (NN) a maior média observada foi no T5 com valores de 24,66\% maiores que o tratamento T1. Para os tratamentos que receberam 50\% da adubação fosfatada, os maiores valores foram observados em T5, T4, T7 e T6 superando em 16,20\%, 12,08\%, 11,24\% e 10,90\%, respectivamente ao tratamento T1 (Tabela 2).

Da mesma forma, para a massa seca de nódulos (MSN) o maior valor médio foi obtido no T3, com valores de $227,46 \%, 46,04 \%, 19,42 \%$ e 17,93\% superiores aos tratamentos T1, T2, T5 e T4, respectivamente. Entre os tratamentos que receberam 50\% da adubação fosfatada, o tratamento T2 foi inferior em 22,29\%, 23,84\%, 30,42\% e 35,27\% comparados aos T5, T4, T6 e T7 respectivamente (Tabela 2). A menor altura média das plantas (ALT), foi verificada no T2, superado pelos tratamentos, T6, T5, T3 e T7 em 17,33\%, 26,61\%, 26,88\% e 29,83\%, respectivamente, sendo que estes apresentaram ALT estatisticamente semelhantes entre si (Tabela 2).

Quanto ao diâmetro de caule (DC), o T3 apresentou maiores valores médios comparados aos demais tratamentos superando em $149,70 \%, 53,45 \%, 42,09 \%, 33,12 \%, 53,61 \%$ e 31,46\% os tratamentos T1, T2, T4, T5, T6 e T7, respectivamente (Tabela 2).

A massa seca total da folha de soja (MSF) foi superior nos tratamentos T3 e T7, que superaram o T1, T2 e T4 em $51,70 \%, 33,91 \%, 119,64 \%$ e 49,33\%, 31,82\% e 45,6\%, respectivamente (Tabela 2). A inoculação de 150 e $200 \mathrm{~mL}, \mathrm{~T} 6$ e T7 
proporcionaram valores superiores em $24,01 \%$ e $31,82 \%$ comparados ao tratamento T2 que recebeu apenas a mesma quantidade de fertilização fosfatada $50 \%$ (Tabela 2).

Verificou-se ao avaliar os resultados obtidos para a área do município de Toledo/PR que todas as variáveis referentes aos nutrientes foliares de soja NIDERA NA 5909 RG estudadas apresentaram efeitos significativos pelo teste $F(p \leq 0,01$ ) (Figura 2).

Para o teor de $\mathrm{N}$ foliar o maior valor médio foi obtido no tratamento T3, seguidos pelos T6 e T7 comparados pelos T1, T2 e T4 (Figura 2 A). Ainda, os tratamentos T3, T6 e T7 apresentaram superioridade de 113,26\%, 60,80\% e 55,95\% ao T1, $62,33 \%, 22,40 \%$ e $18,70 \%$ ao T2 e 53,002\%, 15,38\% e $11,89 \%$ ao T4, respectivamente. Ao analisar somente o comportamento dos tratamentos que receberam $50 \%$ da adubação fosfatada, nota-se que o tratamento que não recebeu a inoculação T4, foi inferior em $06,08 \%, 18,70 \%$ e 22,40\% aos tratamentos T5, T7 e T6, respectivamente (Figura 2 A). 
Figura 2. Teor nutricional de folha (nitrogênio "A", fósforo "C" e potássio "E”) e grão (nitrogênio "B", fósforo "D e potássio "F”), de plantas de soja cultivar soja NIDERA NA 5909 RG cultivadas sobre diferentes doses de inoculação de sementes com P. fluorescens, no município de Toledo/PR. Médias seguidas das mesmas letras minúsculas na coluna não diferem entre si pelo teste de Tukey a 1\%. T1- Controle (sem adubação fosfatada e sem inoculação das sementes); T2- 50\% de adubação fosfatada (super triplo) e sem inoculação; T3- 100\% de adubação fosfatada (super triplo) e sem inoculação; T4- 50\% de adubação fosfatada (super triplo) e inoculação das sementes com o inoculante a base de P. fluorescens, na dose de $50 \mathrm{~mL}^{2} \mathrm{~kg}^{-1} \mathrm{de}$ sementes; T5- 50\% de adubação fosfatada (super triplo) e inoculação das sementes com o inoculante a base de P. fluorescens, na dose de $100 \mathrm{~mL} 50 \mathrm{~kg}^{-1}$ de sementes; T6- 50\% de adubação fosfatada (super triplo) e inoculação das sementes com o inoculante a base de $P$. fluorescens, na dose de $150 \mathrm{~mL} 50 \mathrm{~kg}^{-1}$ de sementes; T7- $50 \%$ de adubação fosfatada (super triplo) e inoculação das sementes com o inoculante a base de $P$. fluorescens, na dose de $200 \mathrm{~mL}^{\circ} \mathrm{kg}^{-1}$ de sementes. Todos os

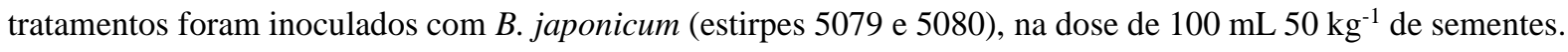
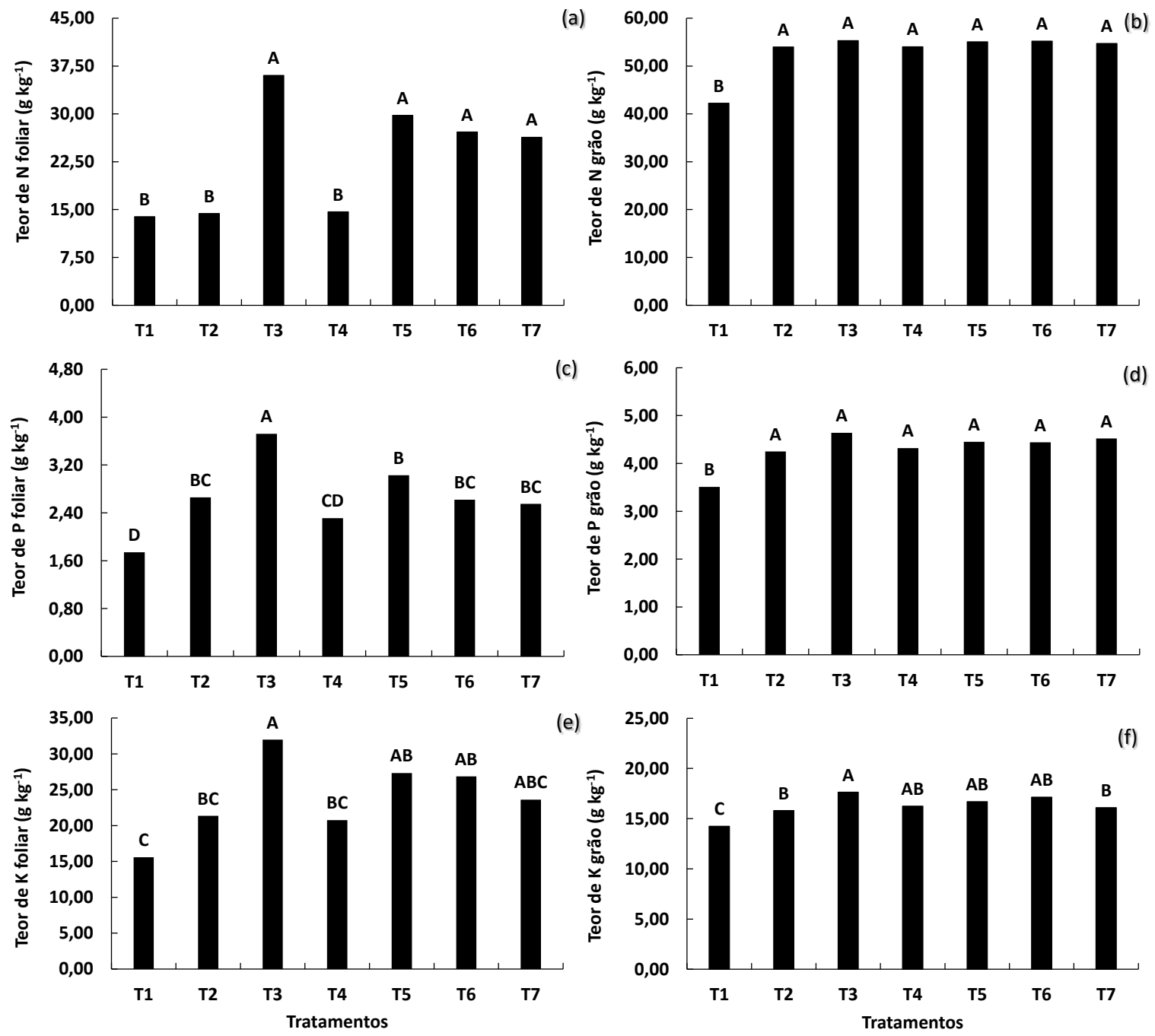

Fonte: Autores.

Ao analisar o teor de P foliar o maior valor foi em T3 superando em 22,77\%, 39,85\%, 41,98\%, 45,88\%, 61,04\% e 113,79\% os tratamentos T5, T2, T6, T7, T4, e T1, respectivamente (Figura 2 B). O teor de K nas folhas de soja foi maior em T3, superando em 53,90\%, 49,72\% e 105,26\% os tratamentos T4, T2 e T1, respectivamente (Figura 2 C).

Os teores médios de $\mathrm{N}$ nos grãos de soja para o tratamento T1 (controle) apresentou inferioridade de 30,36\%, 27,80\%, $30,93 \%, 27,94 \%, 30,71 \%$ e 29,53\% aos T5, T2, T3, T4, T6 e T7, respectivamente (Figura 2 D). Da mesma forma, o teor médio de P nos grãos de soja foi inferior em T1 apresentando valor inferior em 32,19\%, 21,08\%, 23,07\%, 26,78\%, 26,50\% e 28,77\% 
aos tratamentos T3, T2, T4, T5, T6 e T7, respectivamente (Figura 2 E). Quanto ao teor de K, o maior teor nos grãos foi observado no T3, superando em $11,65 \%, 23,81 \%$ e $09,50 \%$ os T2, T1 e T7, respectivamente (Figura 2 F).

A produtividade média de soja NIDERA NA 5909 RG testadas na cidade de Toledo/PR foi maior em T3 superando os tratamentos T1, T2, T4, T5, T6 e T7 em 143,48\%, 87,39\%, 42,76\%, 24,14\%, 37,10\% e 31,41\%, respectivamente (Figura 3). Ainda na mesma figura, verifica-se que todos os tratamentos que receberam inoculação T4, T5, T6 e T7 foram superiores em $31,26 \%, 50,95 \%, 36,68 \%$ e 42,59\% comparados ao tratamento T2 que recebeu a mesma concentração de fertilizante exceto ausência de inoculação.

Figura 3. Produtividade de plantas de soja cultivar soja NIDERA NA 5909 RG cultivadas sobre diferentes doses de inoculação de sementes com $P$. fluorescens, no município de Toledo/PR. Médias seguidas das mesmas letras minúsculas na coluna não diferem entre si pelo teste de Tukey a 5\%; CV $=20,70 \%$; DMS $=738,32$; e F cal = 20,340** . significativo pelo teste $\mathrm{F}$ a $5 \%$ de probabilidade. T1- Controle (sem adubação fosfatada e sem inoculação das sementes); T2- 50\% de adubação fosfatada (super triplo) e sem inoculação; T3- 100\% de adubação fosfatada (super triplo) e sem inoculação; T4- 50\% de adubação fosfatada (super triplo) e inoculação das sementes com o inoculante a base de $P$. fluorescens, na dose de $50 \mathrm{~mL}^{2} \mathrm{~kg}^{-1} \mathrm{de}^{\mathrm{sementes}}$; T5$50 \%$ de adubação fosfatada (super triplo) e inoculação das sementes com o inoculante a base de P. fluorescens, na dose de 100 mL50 kg-1 de sementes; T6- 50\% de adubação fosfatada (super triplo) e inoculação das sementes com o inoculante a base de $P$. fluorescens, na dose de $150 \mathrm{~mL} 50 \mathrm{~kg}^{-1}$ de sementes; T7- $50 \%$ de adubação fosfatada (super triplo) e inoculação das sementes

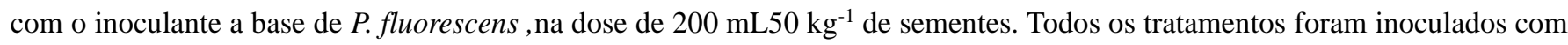
B. japonicum (estirpes 5079 e 5080), na dose de $100 \mathrm{~mL} 50 \mathrm{~kg}^{-1}$ de sementes.

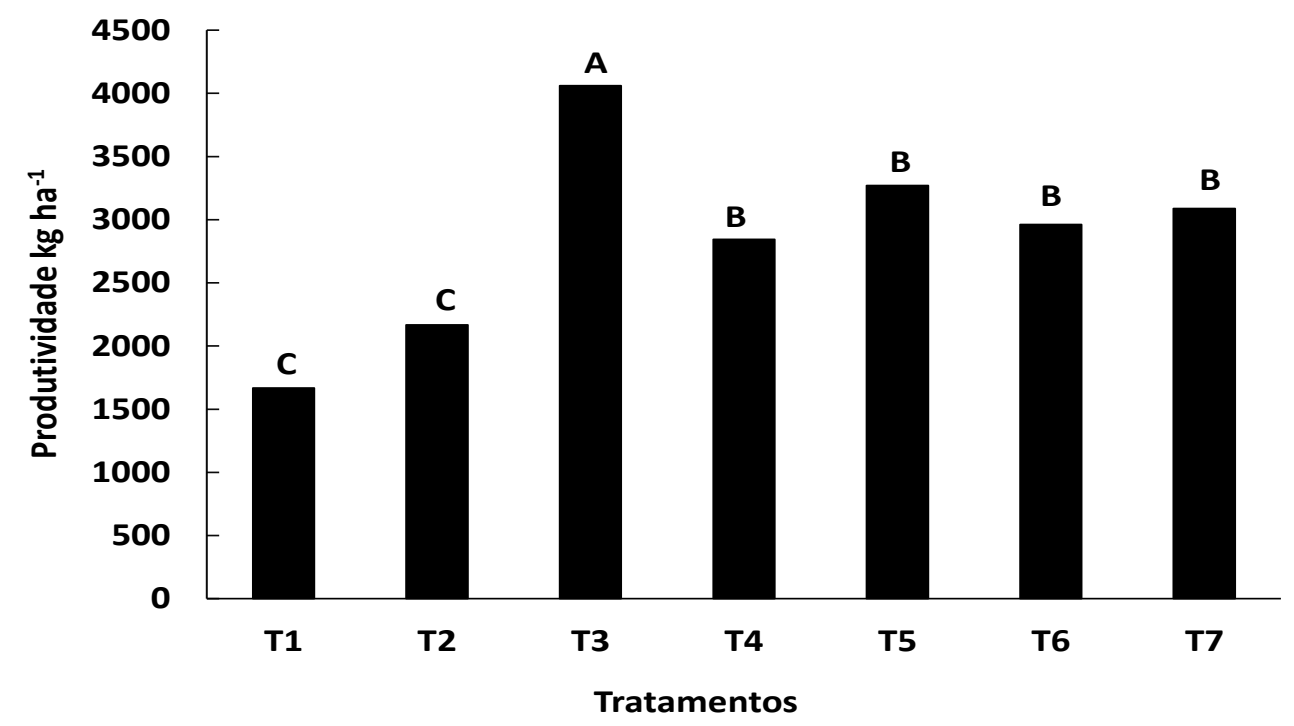

Fonte: Autores.

\section{Área experimental na cidade de Palotina/PR}

Ao avaliar os resultados obtidos para a área do município de Palotina verifica-se que todas as variáveis estudadas apresentaram efeitos significativos pelo teste $\mathrm{F}(\mathrm{p} \leq 0,01)$ (Tabela 3$)$. A massa seca de raiz (MSR), foi superior no tratamento T3, superando em 36,84\%, 50,00\%, 93,39\% e 290,00\% os tratamentos T6, T4, T2 e T1, respectivamente (Tabela 3). Quando analisamos somente os tratamentos que receberam $50 \%$ da adubação fosfatada para esta variável nota-se que os tratamentos que receberam a inoculação de $P$. fluorescens T5 e T7 foram superiores ao tratamento T2 em 69,42\% e 62,81\%, respectivamente (Tabela 3 ). 
Tabela 3. Massa seca de raiz (MSR), número de nódulos por planta (NN), massa seca de nódulos (MSN), altura de planta (ALT), diâmetro de caule (DC), massa seca total de parte aérea (MSTPA), teor de sob diferentes formas nitrogênio na folha (N foliar) e teor de nitrogênio nos grãos (N grãos) de plantas de soja NIDERA NA 5909 RG cultivadas com inoculação de sementes com P. fluorescens e fertilização fosfatada, Município de Palotina/PR.

\begin{tabular}{lllllll}
\hline \multirow{2}{*}{ Trat } & MSR & NN & MSN & ALT & DC & MSF \\
\cline { 2 - 7 } & g planta & mg planta ${ }^{-1}$ & $\mathrm{~cm}$ & $\mathrm{~mm}$ & $\mathrm{~g} \mathrm{planta}^{-1}$ \\
\hline T1 & $0,60 \mathrm{~d}$ & $29,44 \mathrm{~b}$ & $109,40 \mathrm{c}$ & $44,64 \mathrm{c}$ & $0,30 \mathrm{c}$ & $11,76 \mathrm{~d}$ \\
T2 & $1,21 \mathrm{c}$ & $30,02 \mathrm{ab}$ & $244,81 \mathrm{~b}$ & $50,03 \mathrm{~b}$ & $0,50 \mathrm{~b}$ & $12,89 \mathrm{~cd}$ \\
T3 & $2,34 \mathrm{a}$ & $34,31 \mathrm{ab}$ & $365,27 \mathrm{a}$ & $56,67 \mathrm{a}$ & $0,75 \mathrm{a}$ & $17,13 \mathrm{a}$ \\
T4 & $1,56 \mathrm{bc}$ & $34,24 \mathrm{ab}$ & $304,71 \mathrm{ab}$ & $52,83 \mathrm{ab}$ & $0,56 \mathrm{~b}$ & $14,83 \mathrm{bc}$ \\
T5 & $2,05 \mathrm{ab}$ & $35,08 \mathrm{a}$ & $310,35 \mathrm{a}$ & $52,93 \mathrm{ab}$ & $0,53 \mathrm{~b}$ & $16,12 \mathrm{ab}$ \\
T6 & $1,71 \mathrm{bc}$ & $34,24 \mathrm{ab}$ & $315,69 \mathrm{a}$ & $52,14 \mathrm{~b}$ & $0,52 \mathrm{~b}$ & $16,45 \mathrm{ab}$ \\
T7 & $1,97 \mathrm{ab}$ & $34,03 \mathrm{ab}$ & $307,69 \mathrm{ab}$ & $50,39 \mathrm{~b}$ & $0,54 \mathrm{~b}$ & $16,59 \mathrm{ab}$ \\
\hline CV $(\%)$ & 13,79 & 16,73 & 19,75 & 13,55 & 8,93 & 16,03 \\
\hline DMS & 0,52 & 5,20 & 63,74 & 4,27 & 0,11 & 2,13 \\
\hline F cal & $26,75^{* *}$ & $4,281 * *$ & $36,924 * *$ & $16,27 * *$ & $30,742^{* *}$ & $20,325^{* *}$ \\
\hline
\end{tabular}

**significativo pelo teste $\mathrm{F}$ a $5 \%$ de probabilidade. Médias seguidas das mesmas letras minúsculas na coluna não diferem entre si pelo teste de Tukey a 5\% de probabilidade. Coeficiente de variação (CV (\%)); diferença mínima significativa (DMS). T1- Controle (sem adubação fosfatada e sem inoculação das sementes); T2- 50\% de adubação fosfatada (super triplo) e sem inoculação; T3- 100\% de adubação fosfatada (super triplo) e sem inoculação; T4- 50\% de adubação fosfatada (super triplo) e inoculação das sementes com o inoculante a base de P. fluorescens, na dose de 50 mL50 kg ${ }^{-1}$ de sementes; T5- $50 \%$ de adubação fosfatada (super triplo) e inoculação das sementes com o inoculante a base de P. fluorescens, na dose de $100 \mathrm{~mL} 50 \mathrm{~kg}^{-1}$ de sementes; T6- $50 \%$ de adubação fosfatada (super triplo) e inoculação das sementes com o inoculante a base de $P$. fluorescens, na dose de $150 \mathrm{~mL} 50 \mathrm{~kg}^{-1} \mathrm{de}^{-} \mathrm{sementes}$; T7- $50 \%$ de adubação fosfatada (super triplo) e inoculação das sementes com o inoculante a base de P. fluorescens , na dose de $200 \mathrm{~mL}^{2} 0 \mathrm{~kg}^{-1}$ de sementes. Todos os

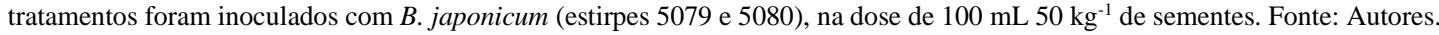

Para o número de nódulos (NN) a maior média observada foi no T5 com valores de 19,16\% maiores que o tratamento T1 (Tabela 3). Da mesma forma, a massa seca de nódulos (MSN) o maior valor médio foi obtido no T3, seguidos por T6 e T5 (Tabela 3). Os tratamentos T3, T6 e T7 superaram 183,68\%, 188,56\% e 233,88\% о T1 e 26,77\%, 28,95\% e 49,21\% o T2, respectivamente (Tabela 3 ).

A maior altura média das plantas de soja (ALT), foi verificada no T3, superando em 08,69\%, 12,46\%, 13,27\% e 26,95\% os tratamentos T6, T7, T2 e T1, respectivamente (Tabela 3). Quanto ao diâmetro de caule (DC), o T3 apresentou maiores valores médios comparados aos demais tratamentos superando em 150,00\%, 50,00\%, 33,93\%, 41,51\%, 44,23\% e 31,46\% os tratamentos T1, T2, T4, T5, T6 e T7, respectivamente (Tabela 3). A massa seca total da folha de soja (MSF) foi superior nos tratamentos T3, superando o T1, T2 e T4 em 45,66\%, 32,89\% e 115,04, respectivamente (Tabela 3).

Ao avaliar os resultados dos teores nutricionais de folha e grão de soja NIDERA NA 5909 RG, verificou-se efeitos significativos pelo teste $\mathrm{F}(\mathrm{p} \leq 0,01)$ (Figura 4). O teor de $\mathrm{N}$ foliar o maior valor médio foi obtido no tratamento T3, superando em 169,04\% e 45,91\% os tratamentos T1 e T2 (Figura 4 A). Quanto ao teor de P foliar o maior valor obtido foi verificado em T3 superando em 43,35\% o tratamento T1 (Figura 4 B).

O teor médio de $\mathrm{K}$ nas folhas de soja foi maior em T6 e T3, superando em 54,63\%, 38,21\%, 36,24\% e 41,71\%, 26,66\% e 24,85\% \% os tratamentos T4, T2 e T1, respectivamente (Figura 4 C). Ao analisar o comportamento apenas dos produtos que receberam $50 \%$ do fornecimento de fosforo, nota-se que o fornecimento de $150 \mathrm{~mL}$ de inoculante em T6 foi superior ao T2 em $38,21 \%$.

Para os teores médios de N nos grãos de soja, verificou-se que o T1 apresentou inferioridade de 26,82\%, 15,57\%, 21,75\%, 19,56\%, 22,86\%, 27,86\%, respectivamente (Figura 4 D). Quanto ao teor médio de P nos grãos de soja, este também 
foi inferior em T1, apresentando valor médios inferior em 20,87\%, 14,36\%, 17,07\%, 14,36\% e 18,70\% comparados aos tratamentos T3, T4, T5, T6 e T7, respectivamente (Figura 4 E).

Já o maior teor de K nos grãos de soja foi encontrado no T3, superando em 11,69\%, 16,79\%, 13,83\%, 16,86\%, $15,61 \%$ e $14,64 \%$ os tratamentos T2, T3, T4, T5, T6 e T7, respectivamente (Figura 4 F).

Figura 4. Teor nutricional de folha (nitrogênio "A", fósforo "C" e potássio "E") e grão (nitrogênio "B", fósforo "D e potássio "F"), de plantas de soja cultivar soja NIDERA NA 5909 RG cultivadas sobre diferentes doses de inoculação de sementes com P. fluorescens, no município de Palotina/PR. Médias seguidas das mesmas letras minúsculas na coluna não diferem entre si pelo teste de Tukey a 1\%. T1- Controle (sem adubação fosfatada e sem inoculação das sementes); T2- 50\% de adubação fosfatada (super triplo) e sem inoculação; T3- 100\% de adubação fosfatada (super triplo) e sem inoculação; T4- 50\% de adubação fosfatada (super triplo) e inoculação das sementes com o inoculante a base de P. fluorescens, na dose de $50 \mathrm{~mL} 50 \mathrm{~kg}$ ${ }^{1}$ de sementes; T5- 50\% de adubação fosfatada (super triplo) e inoculação das sementes com o inoculante a base de $P$. fluorescens, na dose de $100 \mathrm{~mL} 50 \mathrm{~kg}^{-1}$ de sementes; T6- 50\% de adubação fosfatada (super triplo) e inoculação das sementes com o inoculante a base de $P$. fluorescens, na dose de $150 \mathrm{~mL} 50 \mathrm{~kg}^{-1}$ de sementes; T7- $50 \%$ de adubação fosfatada (super triplo) e inoculação das sementes com o inoculante a base de $P$. fluorescens , na dose de $200 \mathrm{~mL}^{-} \mathrm{kg}^{-1} \mathrm{de}_{\mathrm{sem}} \mathrm{sentes}$. Todos os tratamentos foram inoculados com B. japonicum (estirpes 5079 e 5080 ), na dose de $100 \mathrm{~mL} 50 \mathrm{~kg}^{-1}$ de sementes.
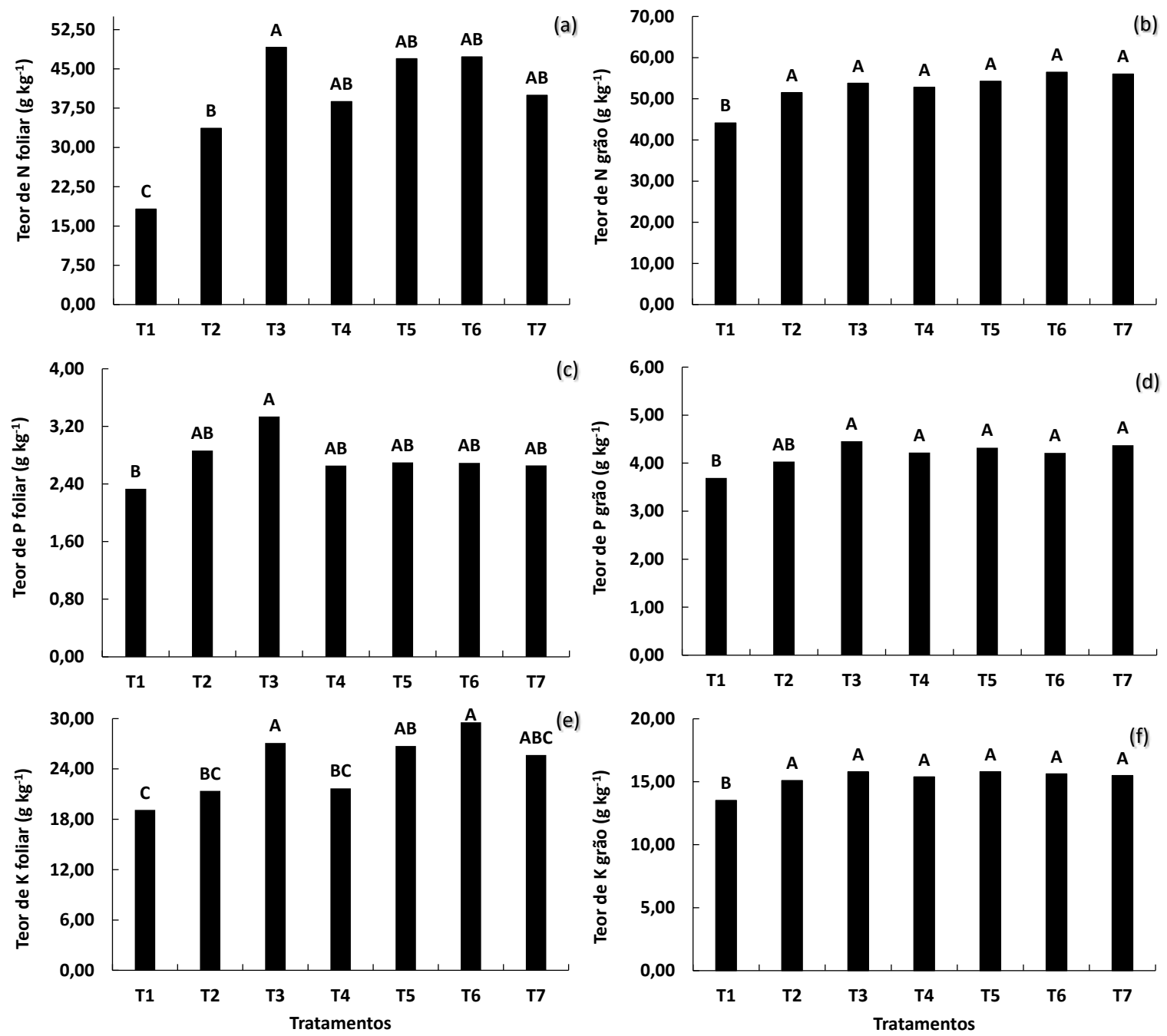

Fonte: Autores.

A maior produtividade de soja cultivada na cidade de Toledo/PR conforme as condições testadas foram obtidas pelo tratamento T3 superando em 143,48\%, 46,75\% 42,75\%, 24,13\%, 37,10\% e 31,41\% os tratamentos T1, T2, T4, T5, T6, e T7, respectivamente (Figura 5). 
Figura 5. Produtividade de plantas de soja cultivar soja NIDERA NA 5909 RG cultivadas sobre diferentes doses de inoculação de sementes com $P$. fluorescens, no município de Palotina/PR. Médias seguidas das mesmas letras minúsculas na coluna não diferem entre si pelo teste de Tukey a 5\%. CV $=17,52 \%$; DMS $=149,07$; e F cal $=43,908 * *$ significativo pelo teste $\mathrm{F}$ a $5 \%$ de probabilidade. T1- Controle (sem adubação fosfatada e sem inoculação das sementes); T2- 50\% de adubação fosfatada (super triplo) e sem inoculação; T3- 100\% de adubação fosfatada (super triplo) e sem inoculação; T4- 50\% de adubação fosfatada (super triplo) e inoculação das sementes com o inoculante a base de $P$. fluorescens, na dose de $50 \mathrm{~mL}^{2} \mathrm{~kg}^{-1} \mathrm{de}$ sementes; T5$50 \%$ de adubação fosfatada (super triplo) e inoculação das sementes com o inoculante a base de P. fluorescens, na dose de 100 mL50 kg-1 de sementes; T6- 50\% de adubação fosfatada (super triplo) e inoculação das sementes com o inoculante a base de $P$. fluorescens, na dose de $150 \mathrm{~mL} 50 \mathrm{~kg}^{-1}$ de sementes; T7- 50\% de adubação fosfatada (super triplo) e inoculação das sementes

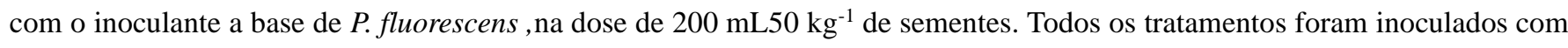
B. japonicum (estirpes 5079 e 5080), na dose de $100 \mathrm{~mL} 50 \mathrm{~kg}^{-1}$ de sementes.

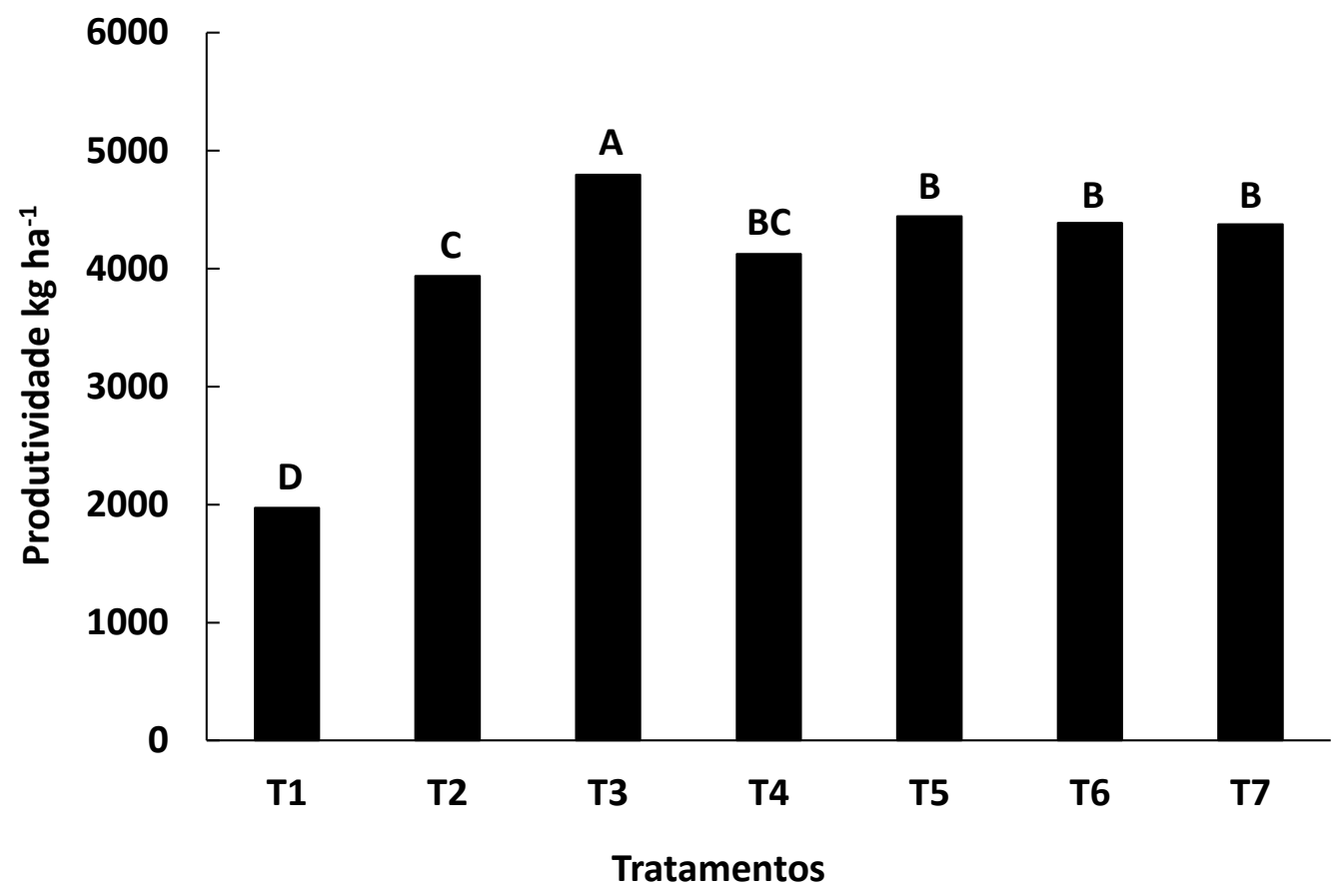

Fonte: Autores.

\section{Área experimental na cidade de São Miguel do Iguaçu/PR}

Analisando os resultados obtidos para a área do município de São Miguel do Iguaçu/PR, verifica-se que todas as variáveis estudadas apresentaram efeitos significativos pelo teste $\mathrm{F}(\mathrm{p} \leq 0,01)$ (Tabela 4$)$.

O maior valor médio de MSR, foi superior no tratamento T3, superando em 500\%, 86,10\%, 80,31\%, 31,82\% e $32,32 \%$ os tratamentos T1, T2, T4, T6 e T7, respectivamente (Tabela 4). Quando analisamos somente os tratamentos que receberam $50 \%$ da adubação fosfatada para esta variável nota-se que os tratamentos que receberam a inoculação de $P$. fluorescens T5, T6 e T7 foram superiores ao tratamento T2 em 56,99\%, 41,94\% e 41,40\%, respectivamente (Tabela 4). 
Tabela 4. Massa seca de raiz (MSR), número de nódulos por planta (NN), massa seca de nódulos (MSN), altura de planta (ALT), diâmetro de caule (DC), massa seca total de parte aérea (MSTPA), teor de sob diferentes formas nitrogênio na folha (N foliar) e teor de nitrogênio nos grãos (N grãos) de plantas de soja NIDERA NA 5909 RG cultivadas com inoculação de sementes com P. fluorescens e fertilização fosfatada, Município de São Miguel do Iguaçu - PR.

\begin{tabular}{|c|c|c|c|c|c|c|}
\hline \multirow{2}{*}{ Trat } & \multirow{2}{*}{$\begin{array}{l}\text { MSR } \\
\text { g planta }^{-1}\end{array}$} & \multirow{2}{*}{$-\mathrm{NN}$} & \multirow{2}{*}{$\frac{\text { MSN }}{\text { mg planta }^{-1}}$} & \multirow{2}{*}{$\begin{array}{l}\text { ALT } \\
\mathrm{cm}\end{array}$} & \multirow{2}{*}{$\frac{\mathrm{DC}}{\mathrm{mm}}$} & \multirow{2}{*}{$\begin{array}{l}\text { MSF } \\
\text { g planta }^{-1}\end{array}$} \\
\hline & & & & & & \\
\hline $\mathrm{T} 1$ & $0,58 \mathrm{~d}$ & $29,72 \mathrm{~b}$ & $158,25 \mathrm{~d}$ & $52,27 \mathrm{c}$ & $44,03 \mathrm{c}$ & $16,85 \mathrm{e}$ \\
\hline $\mathrm{T} 2$ & $1,86 \mathrm{c}$ & $32,94 \mathrm{ab}$ & $346,56 \mathrm{c}$ & $55,25 \mathrm{bc}$ & $74,26 \mathrm{~b}$ & $19,54 \mathrm{~d}$ \\
\hline $\mathrm{T} 3$ & $3,48 \mathrm{a}$ & $36,15 \mathrm{a}$ & $505,54 \mathrm{a}$ & $59,58 \mathrm{ab}$ & $107,52 \mathrm{a}$ & $26,98 \mathrm{a}$ \\
\hline $\mathrm{T} 4$ & $1,93 \mathrm{c}$ & $35,28 \mathrm{a}$ & $432,91 \mathrm{~b}$ & $57,14 \mathrm{abc}$ & $79,01 \mathrm{~b}$ & $20,13 \mathrm{~cd}$ \\
\hline $\mathrm{T} 5$ & $2,92 \mathrm{ab}$ & $35,91 \mathrm{a}$ & $432,91 \mathrm{~b}$ & $59,30 \mathrm{ab}$ & $75,54 \mathrm{~b}$ & $21,78 \mathrm{bcd}$ \\
\hline T6 & $2,64 \mathrm{~b}$ & $35,37 \mathrm{a}$ & $452,28 \mathrm{ab}$ & $61,34 \mathrm{a}$ & $73,75 \mathrm{~b}$ & $22,40 \mathrm{~d}$ \\
\hline $\mathrm{T} 7$ & $2,63 \mathrm{~b}$ & $34,63 \mathrm{ab}$ & $466,65 \mathrm{ab}$ & $60,17 \mathrm{ab}$ & $77,01 \mathrm{~b}$ & $23,96 \mathrm{~b}$ \\
\hline $\mathrm{CV}(\%)$ & 11,96 & 16,60 & 19,88 & 14,03 & 18,81 & 14,67 \\
\hline DMS & 0,64 & 5,29 & 64,15 & 5,45 & 0,16 & 2,37 \\
\hline F cal & $46,738 * *$ & $4,044 *$ & $72,173 * *$ & $7,479 * *$ & $30,374 * *$ & $41,729 * *$ \\
\hline
\end{tabular}

**significativo pelo teste $\mathrm{F}$ a 5\% de probabilidade. Médias seguidas das mesmas letras minúsculas na coluna não diferem entre si pelo teste de Tukey a 5\% de probabilidade. Coeficiente de variação (CV (\%)); diferença mínima significativa (DMS). T1- Controle (sem adubação fosfatada e sem inoculação das sementes); T2- 50\% de adubação fosfatada (super triplo) e sem inoculação; T3- 100\% de adubação fosfatada (super triplo) e sem inoculação; T4- 50\% de adubação fosfatada (super triplo) e inoculação das sementes com o inoculante a base de $P$. fluorescens, na dose de $50 \mathrm{~mL} 50 \mathrm{~kg}^{-1}$ de sementes; T5- 50\% de adubação fosfatada (super triplo) e inoculação das sementes com o inoculante a base de $P$. fluorescens, na dose de $100 \mathrm{~mL} 50 \mathrm{~kg}^{-1}$ de sementes; T6- 50\% de adubação fosfatada (super triplo) e inoculação das sementes com o inoculante a base de $P$. fluorescens, na dose de $150 \mathrm{~mL}^{2} \mathrm{~kg}^{-1}$ de sementes; T7- $50 \%$ de adubação fosfatada (super triplo) e

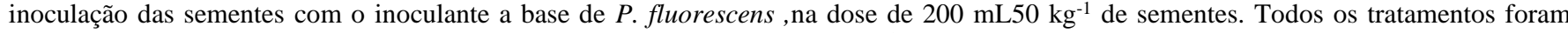

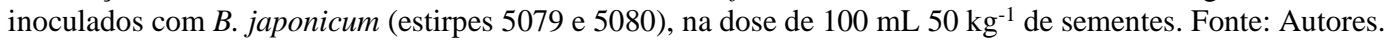

O valor médio de NN foi observado no tratamento T3 seguido pelos T5, T6, T4 e T7 ao superar T1 em 21,64\%, 20,83\%, 19,01\% e 18,71\%, respectivamente. O valor médio da variável MSN foi maior para T3, superando em 219,46\%, $45,87 \% 19,55 \%$ e $16,78 \%$ os tratamentos T1, T2, T4 e T5, respectivamente (Tabela 4). Para a mesma variável, todos os tratamentos que receberam a inoculação independentemente da dose superaram o tratamento T2 em 22,02\%, 24,92\%, 30,51\% e 34,65\%, T4, T5, T6 e T7, respectivamente.

A maior média observada para a variável ALT foi de $61,34 \mathrm{~cm}$, obtida para T6, superando os tratamentos T1 e T2 em 17,35\% e 11,02\%, respectivamente. Para DC das plantas de soja observou-se maior valor médio para T3, superando T1, T2, T4, T5, T6 e T7 em 144,20\%, 44,79\%, 36,08\%, 42,34\%, 45,79\% e 39,62\%, respectivamente (Tabela 4). Quanto à MSF, o maior valor foi em T3 superando em 60,12\%, 38,08\%, 34,03\%, 23,88\%, 20,45\% e 12,60\% os tratamentos T1, T2, T4, T5, T6 e T7, respectivamente (Tabela 4).

Os teores nutricionais de folha e grão de soja (NIDERA NA 5909 RG) referentes ao ensaio do município de São Miguel do Iguaçu/PR, apresentaram efeitos significativos para todas variáveis pelo teste $\mathrm{F}(\mathrm{p} \leq 0,01)$, com exceção do variável teor de $\mathrm{N}$ nas folhas de soja, onde seu efeito significativo foi observado $(\mathrm{p} \leq 0,05)$ (Figura 6$)$.

O maior valor médio do teor de $\mathrm{N}$ nas folhas de soja foi obtido T3, seguidos por T2, T4, T5, T6 e T7 ao comparar com T1 em 78,61\%, 51,33\%, 72,72\%,66,07\%, 69,54\% e 67,80\%, respectivamente (Figura 6 A). O maior valor médio de P nas folhas de soja foi observado no tratamento T3, superando os tratamentos T1, T2, T4, T5 e T6 em 102,41\%, 33,13\%, 42,17\%, $46,39 \%, 51,81 \%$, respectivamente (Figura 6 B).

Os tratamentos T5 e T6 apresentaram valores médios de K nas folhas de soja, superando em 61,27\% e 63,91\% o T1 (Figura 6 C). Por sua vez, T5 apresentou o maior valor médio de N nos grãos de soja seguidos por T4, T5, T6 e T7 superando 
T1 e T2 (Figura 6 D). Tanto T1 foi inferior em 12,64\%, 12,46\%, 13,66\%, 13,40\% e 10,60\%, quanto T2 em 07,13\%, 06,96\%, 08,10\%, 07,86\% e 05,19\% comparados aos tratamentos T3, T4, T5, T6 e T7 (Figura 6 D). Observa-se na mesma figura que esta variável ao analisar o comportamento de todos os tratamentos que receberam inoculação independentemente da formulação foram superiores ao tratamento $\mathrm{T} 2$ com $50 \%$ da dose recomendada, não diferindo do tratamento que recebeu a dose completa T3.

O teor de P nos grãos de soja foi maior no T5, seguidos por T3 e T6 quando comparados a T1 e T2 (Figura 6 E). Os tratamentos T5, T3 e T6 apresentaram superioridade de 34,20\%, 31,90\% e 31,32\% em relação a T1 e 12,26\%, 10,34\% e 09,86\% T2 (Figura 6 E). Os tratamentos T5 e T6 que receberam 100 e $150 \mathrm{~mL}$ do inoculante, apresentaram valores superiores de $12,26 \%$ e $06,25 \%$ comparados ao tratamento T2 (Figura $6 \mathrm{E}$ ).

Por sua vez, o maior teor de K observado nas folhas de soja foi do T3 superando em 31,54\%, 18,49\%, 15,45\%, $14,32 \%, 13,58 \%$ e 14,32\% os tratamentos T1, T2, T4, T5, T6 e T7, respectivamente (Figura 6 F). 
Figura 6. Teor nutricional de folha (nitrogênio "A", fósforo "C" e potássio "E”) e grão (nitrogênio "B", fósforo "D e potássio "F"), de plantas de soja cultivar soja NIDERA NA 5909 RG cultivadas sobre diferentes doses de inoculação de sementes com P. fluorescens, no município de São Miguel do Iguaçu/PR Médias seguidas das mesmas letras minúsculas na coluna não diferem entre si pelo teste de Tukey a 1\%. T1- Controle (sem adubação fosfatada e sem inoculação das sementes); T2- 50\% de adubação fosfatada (super triplo) e sem inoculação; T3- 100\% de adubação fosfatada (super triplo) e sem inoculação; T4- 50\% de adubação fosfatada (super triplo) e inoculação das sementes com o inoculante a base de P. fluorescens, na dose de 50 mL50 $\mathrm{kg}^{-1}$ de sementes; T5- 50\% de adubação fosfatada (super triplo) e inoculação das sementes com o inoculante a base de $P$. fluorescens, na dose de $100 \mathrm{~mL} 50 \mathrm{~kg}^{-1}$ de sementes; T6- 50\% de adubação fosfatada (super triplo) e inoculação das sementes

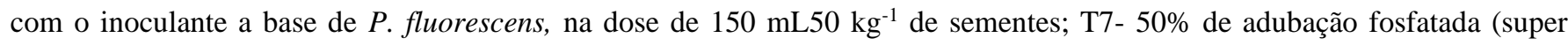
triplo) e inoculação das sementes com o inoculante a base de $P$. fluorescens , na dose de $200 \mathrm{~mL}^{2} \mathrm{~kg}^{-1}$ de sementes. Todos os

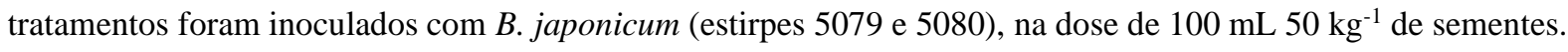
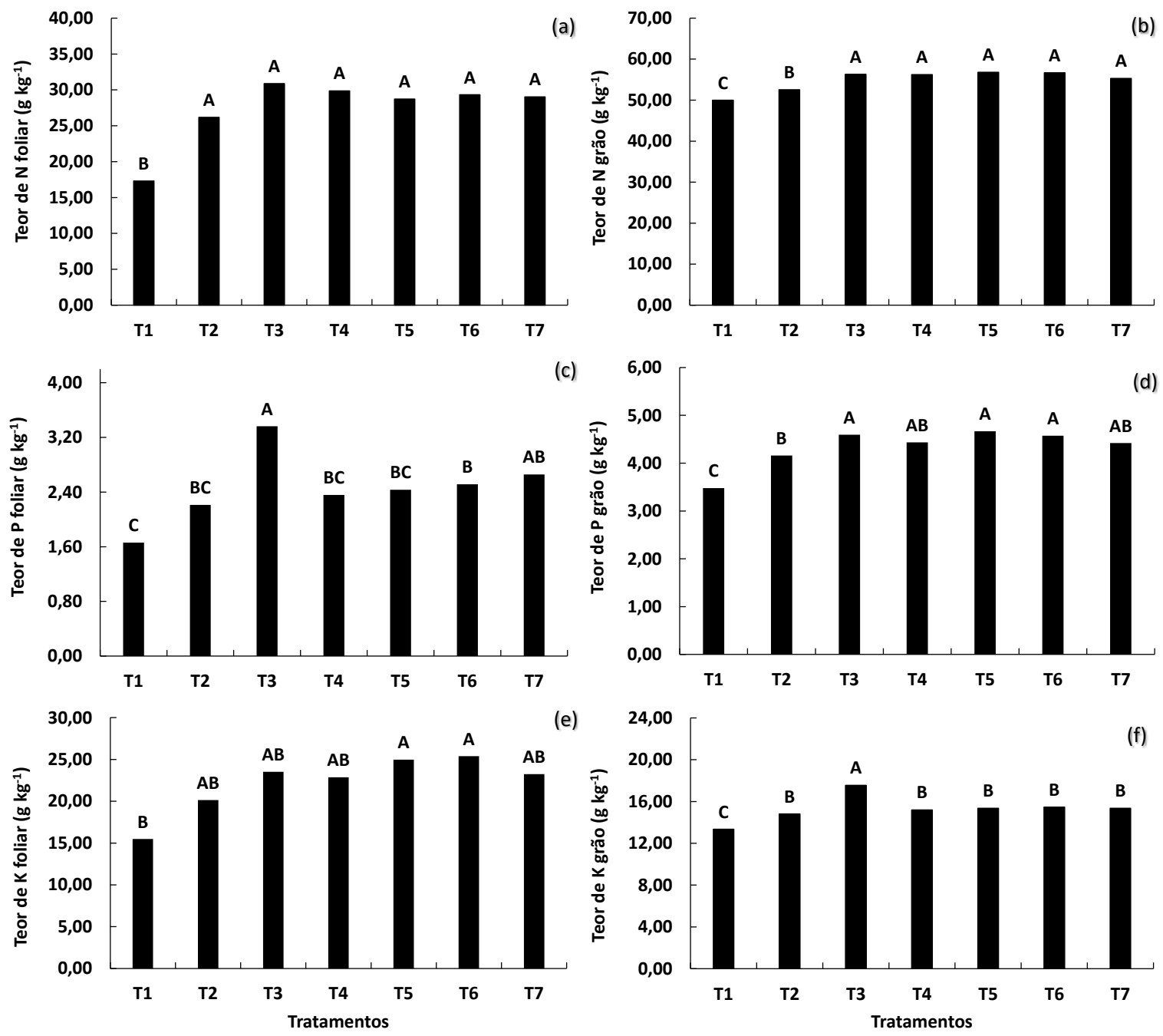

Fonte: Autores.

A maior produtividade de soja cultivada na cidade de Palotina/PR conforme as condições testadas foram obtidas pelo tratamento T3 superando em 143,48\%, 46,75\% 42,75\%, 24,13\%, 37,10\% e 31,41\% os tratamentos T1, T2, T4, T5, T6, e T7, respectivamente (Figura 7). 
Figura 7. Produtividade de plantas de soja cultivar soja NIDERA NA 5909 RG cultivadas sobre diferentes doses de inoculação de sementes com $P$. fluorescens, no município de São Miguel do Iguaçu/PR. Médias seguidas das mesmas letras minúsculas na coluna não diferem entre si pelo teste de Tukey a 5\%. CV =18,08\%; DMS =703,37; e F cal = 29,621** significativo pelo teste $\mathrm{F}$ a $5 \%$ de probabilidade. T1- Controle (sem adubação fosfatada e sem inoculação das sementes); T2- 50\% de adubação fosfatada (super triplo) e sem inoculação; T3- 100\% de adubação fosfatada (super triplo) e sem inoculação; T4- 50\% de adubação fosfatada (super triplo) e inoculação das sementes com o inoculante a base de P. fluorescens, na dose de $50 \mathrm{~mL} 50 \mathrm{~kg}$ ${ }^{1}$ de sementes; T5- 50\% de adubação fosfatada (super triplo) e inoculação das sementes com o inoculante a base de $P$. fluorescens, na dose de $100 \mathrm{~mL} 50 \mathrm{~kg}^{-1}$ de sementes; T6- 50\% de adubação fosfatada (super triplo) e inoculação das sementes

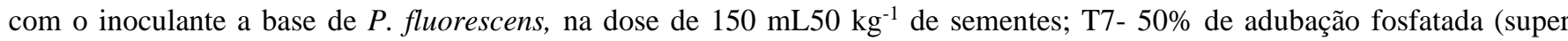
triplo) e inoculação das sementes com o inoculante a base de $P$. fluorescens , na dose de $200 \mathrm{~mL}^{2} \mathrm{~kg}^{-1} \mathrm{de}$ sementes. Todos os

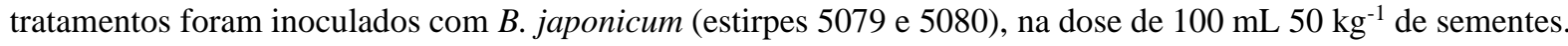

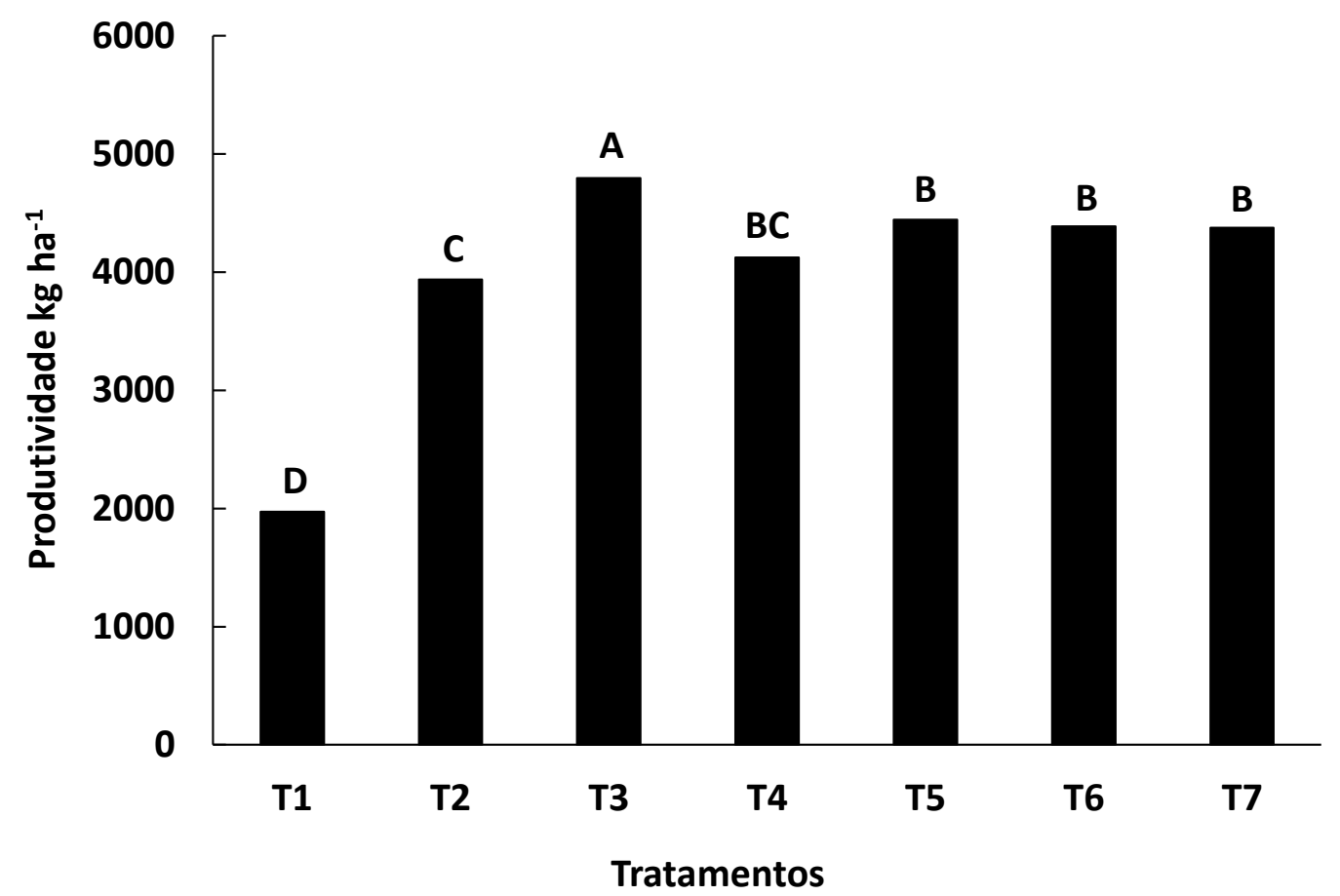

Fonte: Autores.

\section{Área experimental na cidade de Santa Tereza do Oeste/PR}

Ao avaliar os resultados obtidos para Santa Tereza do Oeste/PR, todas as variáveis estudadas apresentaram efeitos significativos pelo teste $\mathrm{F}(\mathrm{p} \leq 0,01)$, com exceção de $\mathrm{NN}$ com significância pelo teste $\mathrm{F}(\mathrm{p} \leq 0,05)$.

Para a variável MSR foi observado o maior valor médio no T3 seguidos por T6, T5 e T7 quando comparados aos T1, T2 e T4 (Tabela 5). Quanto ao número de nódulos (NN) o maior valor médio foi obtido no T7, seguidos por T5, com valores de $42,36 \%$ e $35,35 \%$ maiores que T1, respectivamente (Tabela 5). Foi também observado que a maior média de massa seca de nódulos (MSN) foi no T7 seguidos de T6 e T3 comparados, com valores de 173,11\% e 161,17\% e 161,01\% de T1 e 27,50\%, $21,92 \%$ e $21,84 \%$ de T2 (Tabela 5). 
Tabela 5. Massa seca de raiz (MSR), número de nódulos por planta (NN), massa seca de nódulos (MSN), altura de planta (ALT), diâmetro de caule (DC), massa seca total de parte aérea (MSTPA), teor de sob diferentes formas nitrogênio na folha (N foliar) e teor de nitrogênio nos grãos (N grãos) de plantas de soja NIDERA NA 5909 RG cultivadas com inoculação de sementes com P. fluorescens e fertilização fosfatada, Santa Tereza do Oeste/PR.

\begin{tabular}{|c|c|c|c|c|c|c|}
\hline \multirow{2}{*}{ Trat } & \multirow{2}{*}{$\frac{\text { MSR }}{\text { g planta }^{-1}}$} & \multirow{2}{*}{$-\mathrm{NN}$} & \multirow{2}{*}{$\frac{\text { MSN }}{\text { mg planta }^{-1}}$} & \multirow{2}{*}{$\begin{array}{l}\text { ALT } \\
\mathrm{cm}\end{array}$} & \multirow{2}{*}{$\frac{\mathrm{DC}}{\mathrm{mm}}$} & \multirow{2}{*}{$\frac{\text { MSF }}{\text { g planta }^{-1}}$} \\
\hline & & & & & & \\
\hline $\mathrm{T} 1$ & $0,73 \mathrm{c}$ & $22,52 \mathrm{~b}$ & $168,29 \mathrm{c}$ & $47,33 \mathrm{c}$ & $44,02 \mathrm{~d}$ & $20,07 \mathrm{~d}$ \\
\hline $\mathrm{T} 2$ & $1,82 \mathrm{~b}$ & $29,13 \mathrm{ab}$ & $360,50 \mathrm{~b}$ & $52,13 \mathrm{abc}$ & $68,75 \mathrm{c}$ & $22,91 \mathrm{~cd}$ \\
\hline $\mathrm{T} 3$ & $3,89 \mathrm{a}$ & $28,77 \mathrm{ab}$ & 439,25 a & $53,88 \mathrm{ab}$ & $92,50 \mathrm{a}$ & $32,29 \mathrm{a}$ \\
\hline $\mathrm{T} 4$ & $2,32 \mathrm{~b}$ & $26,04 \mathrm{ab}$ & $412,31 \mathrm{ab}$ & $53,53 \mathrm{abc}$ & $81,11 \mathrm{abc}$ & $24,71 \mathrm{abc}$ \\
\hline $\mathrm{T} 5$ & $3,30 \mathrm{a}$ & $30,48 \mathrm{a}$ & $405,91 \mathrm{ab}$ & $50,88 \mathrm{bc}$ & $82,75 \mathrm{ab}$ & $26,87 \mathrm{abc}$ \\
\hline T6 & $3,35 \mathrm{a}$ & $27,60 \mathrm{ab}$ & $439,53 \mathrm{a}$ & $57,45 \mathrm{a}$ & $77,51 \mathrm{bc}$ & $27,10 \mathrm{abc}$ \\
\hline $\mathrm{T} 7$ & $3,29 \mathrm{a}$ & $32,06 \mathrm{a}$ & $459,62 \mathrm{a}$ & $54,13 \mathrm{ab}$ & $83,25 \mathrm{ab}$ & $29,51 \mathrm{ab}$ \\
\hline $\mathrm{CV}(\%)$ & 13,49 & 21,45 & 18,63 & 15,29 & 17,30 & 19,26 \\
\hline DMS & 0,18 & 7,52 & 77,39 & 6,53 & 0,13 & 5,45 \\
\hline F cal & $37,717 * *$ & $3,769 *$ & $36,618 * *$ & $5,060 * *$ & $32,157 * *$ & $12,270 * *$ \\
\hline
\end{tabular}

**significativo pelo teste $\mathrm{F}$ a $5 \%$ de probabilidade. Médias seguidas das mesmas letras minúsculas na coluna não diferem entre si pelo teste de Tukey a 5\% de probabilidade. Coeficiente de variação (CV (\%); diferença mínima significativa (DMS). T1- Controle (sem adubação fosfatada e sem inoculação das sementes); T2- 50\% de adubação fosfatada (super triplo) e sem inoculação; T3- 100\% de adubação fosfatada (super triplo) e sem inoculação; T4- 50\% de adubação fosfatada (super triplo) e inoculação das sementes com o inoculante a base de P. fluorescens, na dose de 50 mL50 kg ${ }^{-1}$ de sementes; T5- $50 \%$ de adubação fosfatada (super triplo) e inoculação das sementes com o inoculante a base de P. fluorescens, na dose de $100 \mathrm{~mL} 50 \mathrm{~kg}^{-1} \mathrm{de}$ sementes; T6- $50 \%$ de adubação fosfatada (super triplo) e inoculação das sementes com o inoculante a base de P. fluorescens, na dose de $150 \mathrm{~mL}^{2} 0 \mathrm{~kg}^{-1}$ de sementes; T7- $50 \%$ de adubação fosfatada (super triplo) e inoculação das sementes com o inoculante a base de P. fluorescens , na dose de $200 \mathrm{~mL}^{2} 0 \mathrm{~kg}^{-1}$ de sementes. Todos os

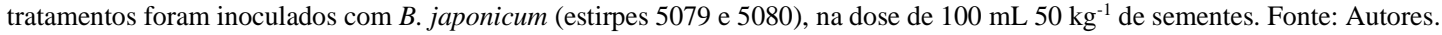

A maior média em ALT foi observada em T6 superando em 21,38\% e 12,91\% T1 e T5, respectivamente (Tabela 5). Valor médio para DC foi maior em T3 superando T1, T2 e T6 em 110,13\%, 34,55\% e 19,34\%, respectivamente (Tabela 5). Para esta mesma variável os tratamentos que receberam a inoculação de 100, 150 e $200 \mathrm{~mL}$ de inoculantes foram superiores ao tratamento T2 em 20,36\%, 12,74\% e 21,09\%, respectivamente.

O maior valor médio de MSF foi obtido para T3 superando em 60,89\% e 40,94\% T1 e T2, respectivamente (Tabela 5). O tratamento que recebeu $200 \mathrm{~mL}$ de inoculantes $\mathrm{T} 7$ superou o $\mathrm{T} 2 \mathrm{em} \mathrm{28,81 \%}$ (Tabela 5). Todos os tratamentos que receberam inoculação, T4, T5, T6 e T7 não diferiram do tratamento que recebeu a dose cheia T3 (Tabela 5).

A análise dos resultados dos teores nutricionais de folha e grão de soja NIDERA NA 5909 RG estudadas na cidade de Santa Tereza do Oeste/PR, apresentaram efeitos significativos para todas variáveis pelo teste $\mathrm{F}$ ( $\mathrm{p} \leq 0,01$ ), com exceção da variável teor de $\mathrm{N}$ nas folhas de soja, onde seu efeito significativo foi observado $(\mathrm{p} \leq 0,05)$ (Figura 8 ). 
Figura 8. Teor nutricional de folha (nitrogênio "A", fósforo "C" e potássio "E”) e grão (nitrogênio "B", fósforo "D e potássio "F"), de plantas de soja cultivar soja NIDERA NA 5909 RG cultivadas sobre diferentes doses de inoculação de sementes com P. fluorescens, no município de Santa Tereza do Oeste/PR. Médias seguidas das mesmas letras minúsculas na coluna não diferem entre si pelo teste de Tukey a 1\%. T1- Controle (sem adubação fosfatada e sem inoculação das sementes); T2- 50\% de adubação fosfatada (super triplo) e sem inoculação; T3- 100\% de adubação fosfatada (super triplo) e sem inoculação; T4- 50\% de adubação fosfatada (super triplo) e inoculação das sementes com o inoculante a base de P. fluorescens, na dose de 50 mL50 $\mathrm{kg}^{-1}$ de sementes; T5- 50\% de adubação fosfatada (super triplo) e inoculação das sementes com o inoculante a base de $P$. fluorescens, na dose de $100 \mathrm{~mL} 50 \mathrm{~kg}^{-1}$ de sementes; T6- 50\% de adubação fosfatada (super triplo) e inoculação das sementes

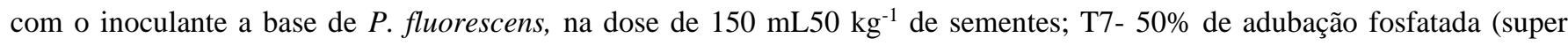
triplo) e inoculação das sementes com o inoculante a base de $P$. fluorescens , na dose de $200 \mathrm{~mL}^{2} \mathrm{~kg}^{-1}$ de sementes. Todos os

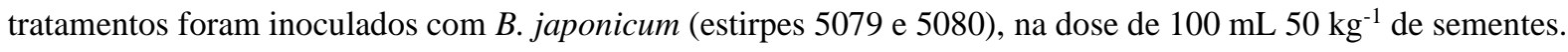
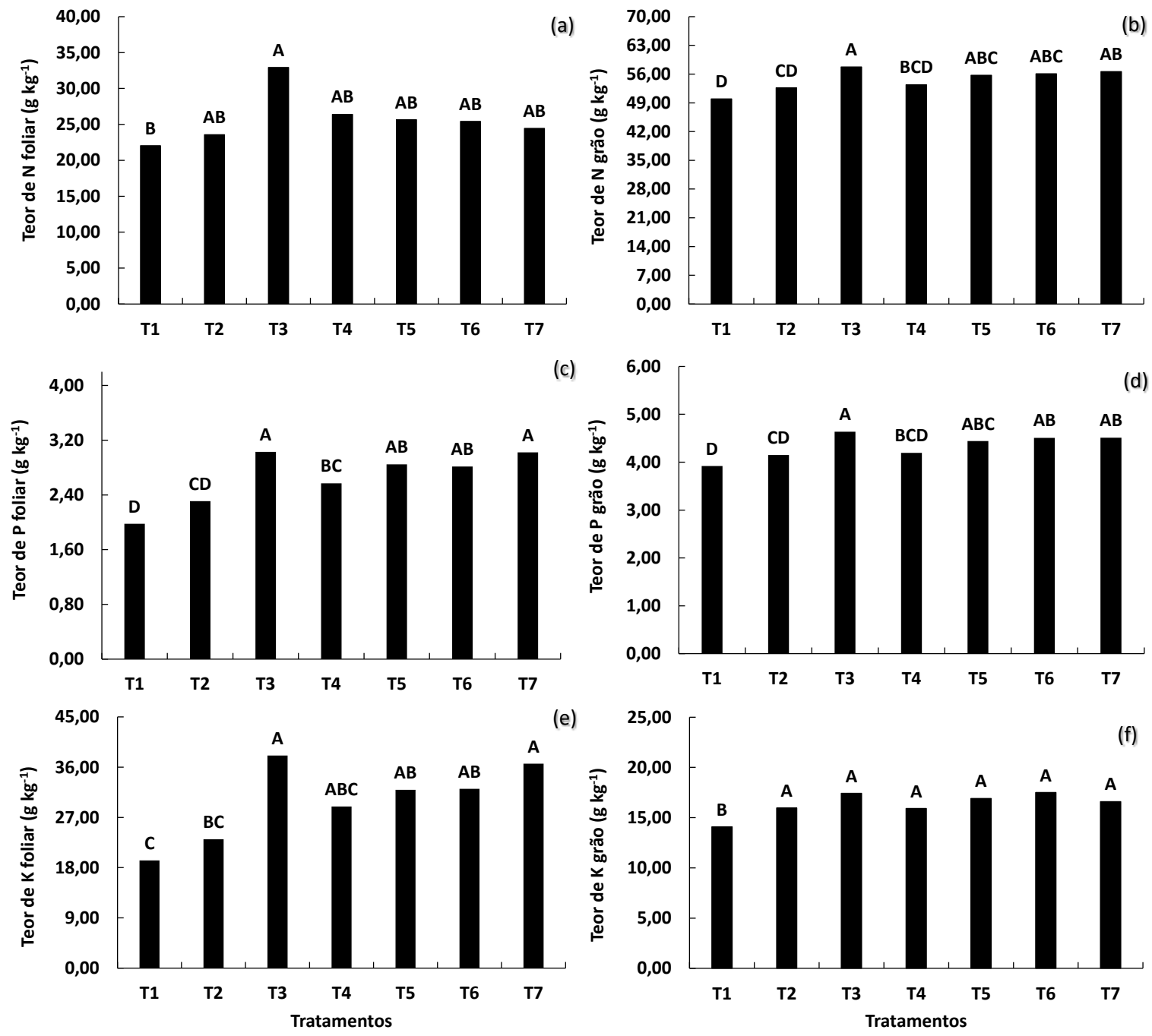

(e) $\quad 25,00$

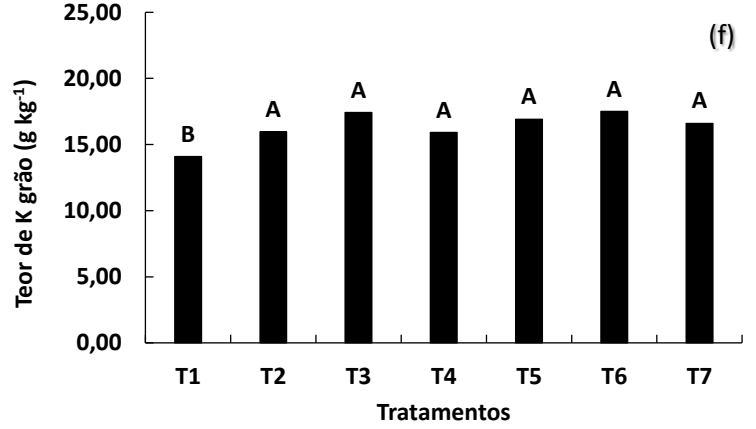

Fonte: Autores.

Para o teor de $\mathrm{N}$ foliar as maiores médias foram obtidas em T3 superando T1 em 49,48\% (Figura 8 A). Na mesma figura, verifica-se que os tratamentos que receberam a inoculação não diferiram do tratamento com dose completa de fósforo. O teor médio de $\mathrm{P}$ na folha de soja foi observado em T3 superando T1, T2 e T4 em 53,03\%, 31,17\% e 17,90\%, respectivamente (Figura 8 B). Verificou-se também que o tratamento T2 foi inferior em 23,38\%, 22,08\% e 30,74\% os tratamentos T5, T6 e T7, respectivamente (Figura 8 B).

Para a variável teor de $\mathrm{K}$ nas folhas de soja o maior valor médio foi observado no T3 superando em 97,56\% e 65,11\% T1 e T2, respectivamente (Figura $8 \mathrm{C}$ ). Ainda na mesma figura, o tratamento que recebeu $50 \%$ da dose fosfatada T2, foi 
inferior 58,69\% o tratamento que recebeu a mesma quantidade de fertilizante associada a $200 \mathrm{~mL}$ de inoculante T7. Os tratamentos que receberam inoculação independentemente da concentração T4, T5, T6 e T7, não diferiram do tratamento que recebeu dose cheia T3 (Figura $8 \mathrm{C}$ ).

$\mathrm{O}$ maior valor médio do teor de $\mathrm{N}$ dos grãos de soja foi observado no tratamento T3 superando T1, T2 e T4 em 15,60\%, 09,62\% e 08,07\%, respectivamente (Figura 8 D). Da mesma forma que o tratamento T7 foi superior ao T2 em 07,50\%. Já, os tratamentos T5, T6 e T7 apresentaram resultados semelhantes ao tratamento que recebeu dose completa de fertilizantes (Figura 8 D.).

Para a variável teor de P nos grãos de soja foi maior em T3 superando em 18,37\%, 05,87\% e 07,14\% os tratamentos T1, T2 e T4, respectivamente (Figura 8 E). O tratamento T2 foi inferior ao T7 em 08,67\%. O tratamento T3 apresentou comportamento semelhante aos tratamentos T5, T6 e T7 (Figura 8 E). O teor médio de K nos grãos de soja foi maior em T6 seguidos por T3, T2, T4, T5 e T7 comparados ao T1 (Figura 8 F). Nesta condição, T1 foi inferior em 24,11\%, 23,62\%, $12,84 \%, 19,93 \%$ e $17,73 \%$ os T3, T2, T4, T5 e T7, respectivamente (Figura 8 F).

A maior produtividade da cultura da soja ocorreu no T7 sem diferenciar do T6 e T5, enquanto a menor produtividade novamente ocorreu em T1. A produtividade em T7 em relação as ao T1 foi de $70 \%$ superior, e em relação ao T2 e T4 foi de $10,9 \%$ e $13,7 \%$ superior, respectivamente (Figura 9).

Figura 9. Produtividade de plantas de soja cultivar soja NIDERA NA 5909 RG cultivadas sobre diferentes doses de inoculação de sementes com P. fluorescens, no município de Santa Tereza do Oeste/PR. ** Médias seguidas das mesmas letras minúsculas na coluna não diferem entre si pelo teste de Tukey a 5\%. CV $=15,65 \%$; DMS $=529,32$; e $\mathrm{F}$ cal: $=68,241 * *$ significativo pelo teste $\mathrm{F}$ a $5 \%$ de probabilidade. T1- Controle (sem adubação fosfatada e sem inoculação das sementes); T2$50 \%$ de adubação fosfatada (super triplo) e sem inoculação; T3- 100\% de adubação fosfatada (super triplo) e sem inoculação; T4- 50\% de adubação fosfatada (super triplo) e inoculação das sementes com o inoculante a base de P. fluorescens, na dose de 50 mL50 kg-1 de sementes; T5- 50\% de adubação fosfatada (super triplo) e inoculação das sementes com o inoculante a base de $P$. fluorescens, na dose de $100 \mathrm{~mL} 50 \mathrm{~kg}^{-1}$ de sementes; T6- 50\% de adubação fosfatada (super triplo) e inoculação das sementes com o inoculante a base de $P$. fluorescens, na dose de $150 \mathrm{~mL} 50 \mathrm{~kg}^{-1}$ de sementes; T7- 50\% de adubação fosfatada (super triplo) e inoculação das sementes com o inoculante a base de $P$. fluorescens, na dose de $200 \mathrm{~mL}^{2} \mathrm{~kg}^{-1}$ de sementes.

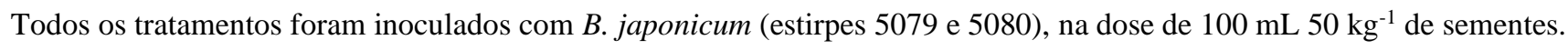

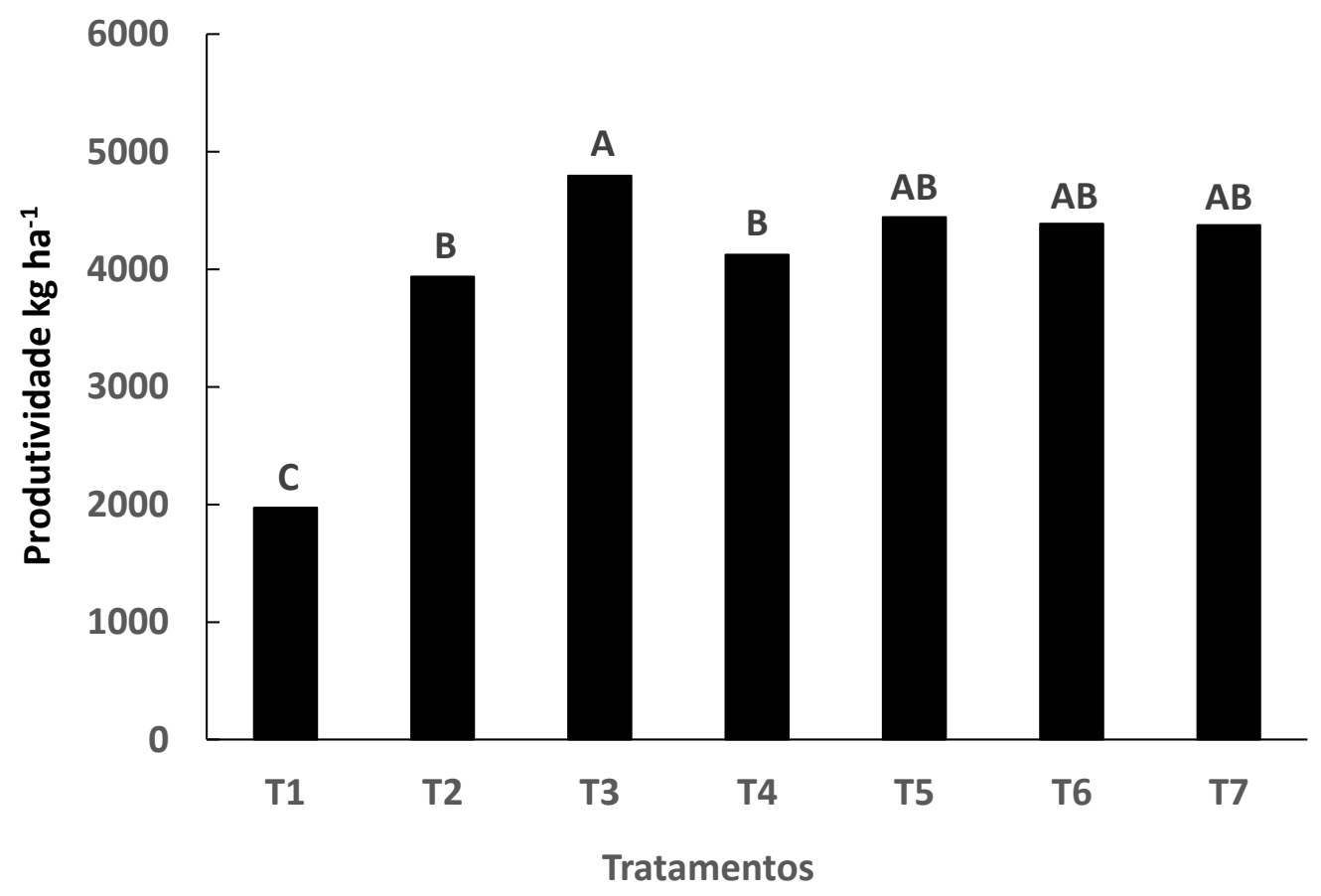

Fonte: Autores. 


\section{Discussão}

A soja é considerada uma das culturas oleaginosas mais produzida e importante do mundo (USDA, 2016). Necessita de uma alta demanda de tecnologia e insumos agrícolas, o que acaba por gerar elevados preços e custo final, além de provocar direta e indiretamente impactos ambientais em aspecto global, uma vez que grande parte dos fatores de produção empregados são altamente dependentes de fontes não renováveis. Associado a este fato, o aumento populacional a nível mundial prevê ainda elevada demanda da agricultura com maiores produtividades, mantendo a área ou aumentando pouco a área de cultivo.

Além disso, é fundamental relembrar que o sistema de cultivo de soja do Brasil é reconhecido mundialmente pelo seu menor impacto ambiental, devido principalmente ao processo natural da fixação biológica de nitrogênio (FBN), realizada por bactérias e outros microrganismos. Esta técnica, de modo geral possibilitou o cultivo da soja com doses mínimas de fertilizante nitrogenado, mantendo os padrões de produtividade, o que gera grande economia e estimula toda a cadeia produtiva da soja, além da redução dos impactos ambientais.

Ao analisar as características do solo, é importante lembrar que a proporção viva do solo pode variar conforme o sistema de cultivo, sazonalidade, disponibilidade de água, dentre outros fatores. Sabe-se que estes microrganismos contribuem para melhoria do sistema de produção por incrementar características físicas, químicas e biológicas do solo, pois solos produtivos geralmente são fisicamente estruturados, quimicamente equilibrados e biologicamente ativos.

Em solos tropicais, além do nitrogênio, o fósforo é um dos mais importantes nutrientes, sendo limitante para a produtividade da cultura da soja. Neste sentido, a literatura apresenta inúmeros microrganismos têm o potencial de contribuir no processo de solubilização e mineralização de fosforo no solo, conforme descrito pela EMBRAPA (2003). Estes autores acreditam que os diferentes microrganismos interferem positivamente na habilidade das plantas em aproveitar o P do solo por diferentes processos e mecanismos. A promoção de crescimento é outra característica importante proveniente da interação de microrganismos com as plantas. As substâncias produzidas desta interação podem estimular o crescimento do sistema radicular e de toda a planta.

Neste estudo, foi possível verificar nos diferentes locais, de modo geral, que a inoculação das sementes da cultivar de soja NIDERA NA 5909, com P. fluorescens influenciou positivamente vários parâmetros morfométricos refletindo em ganhos significativos em matéria seca. Outros benefícios observados foram incrementos nos teores de nutrientes dos tecidos vegetais. Vale destacar que até mesmo o número de nódulos por planta sofreu incremento na grande maioria das áreas testadas.

Estudos realizados com objetivo de determinar a influência de inoculação de $P$. fluorescens e adubação de NPK na composição química e contaminação de fungo-fumonisina de milho, resultou em aumento no teor de cinzas e proteína, além de reduzir a contaminação por leveduras no grão, favorecendo o crescimento de Fusarium spp. (BERND, et al., 2014). Também, na cultura do milho, em trabalhos realizados por Andreotti et al. (2008); Gonçalves Júnior et al. (2008) e Oliveira, et al., (2012) foi constatada que a inoculação das sementes com P. fluorescens aumentou a massa de 100 grãos, o que culminou no aumento da produtividade.

Para Bashan e Bashan (2004), o aumento da biomassa e nos teores de P em plantas é o principal indicativo do efeito da solubilização de fosfato que pode resultar em estímulo ao crescimento e desenvolvimento vegetal. A de $P$. fluorescens podem ser considerada bactéria solubilizadoras de fosfato do solo, tanto orgânico quanto inorgânico. Conforme Nahas et al. (1994), estes microrganismos podem produzir algumas enzimas fosfatases que liberam íons fosfato de substâncias orgânicas das frações do solo. Da mesma forma que na sua solubilização do fósforo da fração inorgânica liberam fosfatos e cátions de cálcio e ferro ao solo conforme observado por Alexander (1980).

Em trabalho conduzido por Pommorsky (2015), na busca de novas biotecnologias para o sistema produtivo da soja, este concluiu que a co-inoculação de P. fluorescens, Ensifer fredii e Paenibacillus edaphicus, associadas a rizóbios, foi eficiente na nodulação, desenvolvimento e rendimento da cultura, corroborando os resultados obtidos por este estudo. O 
mesmo autor ainda menciona que esta combinação de microrganismos pode incrementar $84 \%$ no número de nódulos, quando comparado ao tratamento que utilizou somente bactérias simbiontes de soja E. fredii, B. japonicum e B. elkanii.

Segundo Yadav et al. (2016) o efeito da promoção do crescimento de plantas realizadas por rizobacterias pode ser mediado por mecanismos diretos como a solubilização de fosfato, produção de auxinas, giberelinas, citocinas ou até mesmo no fornecimento de nitrogênio biologicamente fixado. Tal condição é possível devido à sobrevivência dos diferentes microorganismos do solo principalmente aqueles com capacidade de solubilizar fosfato inorgânico insolúvel através da atividade da fosfatase. Visto que em seu trabalho verificou que biovares de $P$. fluorescens isoladas da rizosfera de trigo junto com Bacillus megaterium produziram atividade de solubilização do fosfato em quatro valores diferentes de $\mathrm{pH}$. Ainda estes autores concluiram que de todos os diferentes isolados a máxima produção de fosfato solubilizado foi observada em $\mathrm{pH} 5$ reduzindo drasticamente em $\mathrm{pH} 8$, sendo as bacterias de $P$. Fluorescens considerada o solubilizador de fosfato mais eficiente sugerindo sua exploração comercial.

Levando-se então, em consideração os vários resultados da literatura e os resultados obtidos nos experimentos desenvolvidos neste presente estudo verific-se o potencial da Pseudomonas florescens em promover ganhos em crescimento e produtividade na cultura da soja, nas condiões de estudo, podendo associar estes resultados à solubilização de fosfatos e promoção de crescimento vegetal.

\section{Conclusão}

Baseando-se nos resultados obtidos nos quatro ensaios conduzidos pode-se concluir que:

A inoculação de sementes de soja com Pseudomonas fluorescens, Cepa ATCC 13525, formulação líquida, na dose de $100 \mathrm{~mL}$ para $50 \mathrm{~kg}$ de sementes, coinoculada com Bradyrhizobium japonicum, sendo fornecida a metade da dose de fertilizante fosfatado, se mostrou agronomicamente eficiente resultando ganhos em crescimento e desenvolvimento da cultura, mantendo ou elevando a produtividade, quando comparado à condição em que foi fornecida a dose total de fertilizante fosfatado, sendo esta eficiente em disponibilizar fósforo para a cultura, o que pode contribuir para a sustentabilidade na agricultura e maiores ganhos para a cadeia produtiva da soja.

\section{Agradecimento:}

Ao CNPq, pela bolsa de produtividade em pesquisa concedida ao primeiro autor do artigo e à empresa Fertibio Do Brasil Industria De Fertilizantes LTDA, por ceder o inoculante para o desenvolvimento da pesquisa.

\section{Referências}

Andrade, R. S., Stone, L. F., \& Silveira, P. M. Culturas de cobertura e qualidade física de um Latossolo em plantio direto. Revista Brasileira de Engenharia Agrícola e Ambiental, 13, 411-418.

Araujo, F. F., L. M., Guaberto, L. M., \& Silva, I. F. da. Bioprospecção de rizobactérias promotoras de crescimento em Brachiaria brizantha. Revista Brasileira de Zootecnia. 41, 521-527.

Bárbaro, I. M., Machado, P. C., Bárbaro Junior, L. S., Ticelli, M., Miguel, F. B., \& Silva, J. A. A. da. Produtividade da soja em resposta a inoculação padrão e co-inoculação. Colloquium Agrariae, 5, 1-7.

Bárbaro, I. M., Barbaro Junior, L.S., Ticelli, M., Machado, P. C., M., \& Miguel, F. B. (2011) Resultados preliminares da co-inoculação de Azospirillum juntamente com Bradyrhizobium em soja. Pesquisa \& Tecnologia. 8, 1-6.

Bashan, Y., Holguin, G., \& Bashan, L. E. de. (2004) Azospirillum-plant relationships: physiological, molecular, agricultural, and environmental advances (1997-2003). Canadian Journal of Microbiology, 50, 521-577

Benintende, S., Uhrich, W., Herrera, M., Gangge, F., \& Benintende, M. S. M. (2010) Comparación entre coinoculación com Bradyrhizobium japonicum y Azospirillum brasilense e inoculación simples com Bradyrhizobium japonicum em la nodulación, crecimiento y acumulación de N e nel cultivo de soja. Agriscientia, 27, 71-77 
Bernd, L. P., Souza, T. M., \& Oliveira, M. A. de. Inoculação de Pseudomonas fluorescens e adubação NPK na composição química e contaminação fungofumonisina de milho. Revista Brasileira de Engenharia Agrícola e Ambiental, 18, 1274-1280, 2014

Bolan, N. S., Elliott, J., Gregg, P. E. H., \& Weil, S. Enhanced dissolution of phosphate rocks in the rhizosphere. Biology and Fertility of Soils, 24, 169-174, 1997.

Braccini, A. L. Mariucci. G. E. G., Suzukawa, A. K., Lima, L. H.da S., \& Piccinin, G. G. Co-inoculação e modos de aplicação de Bradyrhizobium japonicum e Azospirillum brasilense e adubação nitrogenada na nodulação das plantas e rendimento da cultura da soja. Scientia Agraria Paranaensis, 15, 27-35.

Brady, N. C., Weil, R. R. The nature and properties of soils. (11a ed.), Prentice Hall, 1996.

Brasil. Ministério da Agricultura, Pecuária e Abastecimento. Instrução normativa n³0, de 12 de novembro de 2010. Estabelece os métodos oficiais para análise de inoculantes, sua contagem, identificação e análise de pureza.Diário Oficial [da] República Federativa do Brasil, 17 nov. 2010. Seção 1, p.4-10.

Bulegon, L. G., Guimarães, V. F., Egewarth, V. A., Santos, M. G., Heling, A. L., Ferreira, S. D., Wengrat, A. P. G. S., \& Battistus, A. G. Crescimento e trocas gasosas no período vegetativo da soja inoculada com bactérias diazotróficas. Nativa, 4, 277-286

Bulegon, L. G., Rampim, L., Klein, J., Kestring, D., Guimarães, V. F., Battistus, A. G., \& Inagaki, A. M. Componentes de produção e produtividade da cultura da soja submetida à inoculação de Bradyrhizobium and Azospirillum. Terra Latinoamericana, 34, 169-176

Caetano-Anollés, G. Molecular dissection and improvement of the nodule symbiosis in legumes. Field Crops Research, 53, 47-68

Cassán, F., Perrig, D., Sgroy, V., Masciarelli, O., Penna, C., \& Luna, V. Azospirillum brasilense Az39 and Bradyrhizobium japonicum E109, inoculated singly or in combination, promote seed germination and early seedling growth in corn (Zea mays L.) and soybean (Glycine max L.). European Journal of Soil Biology, v. 45, n. 1, p. 28-35, jan. 2009.

Chaves, D. P., Zucareli, C., \& Oliveira-Junior, A. Fontes de fósforo associadas à inoculação com Pseudomonas fluorescens no desenvolvimento e produtividade do milho. Semina: Ciências Agrárias, 34, 57-72

Companhia Nacional De Abastecimento. Acompanhamento de safra brasileira: grãos, 12o Levantamento - Safra $2018 / 2019$. Disponível em: https://www.conab.gov.br/info-agro/safras/graos/boletim-da-safra-de-graos.

Dardanelli, M. S., Fernández De Córdoba, F. J., Espuny, M. R., Rodríguez Carvajal, M. A., Soria Díaz, M. E., Gil Serrano, A. M., Okon, Y., \& Megías, M. Effect of Azospirillum brasilense coinoculated with Rhizobium on Phaseolus vulgaris flavonoids and Nod fator production under salt stress. Soil Biology and Biochemistry, 40, 2713-2721

Döbereiner, J., Baldani, V. L. D., \& Baldani, J. I. Como isolar e identificar bactérias diazotróficas de plantas não-leguminosas. Brasília, EMBRAPA-SPI e Seropédica, EMBRAPA-CNPAB, 1995. 60p.

EMBRAPA SOJA. Tecnologias de produção de soja - região central do brasil 2012 e 2013. Londrina: Embrapa Soja, 2011.

EMBRAPA. Manual de métodos de análise de solo / Teixeira, P. C., Donagemma, G. K., Wenceslau, A. F., Teixeira, G., \& editores técnicos. (3a ed.), Embrapa, 2017. 574 p.

Fagan, E. B., Medeiros, S. L. P., Manfron, P. A., Casaroli, D., Simon, J., Neto, D. D., Lier, Q. D. J. Van, \& Santos, O. S. Fisiologia da fixação biológica do nitrogênio em soja - revisão. Revista FZVA, 14, 89-106

Fei, H., \& Vessey, J. K. Further investigation of the roles of auxin and cytokinin in the NH4+-induced stimulation of nodulation using white clover transformed with the auxin-sensitive reporter GH3: gusA. Physiologia Plantarum121, 674-681

Ferreira, D. F. SISVAR - Sistema de análise de variância. Ciência e tecnologia, lavras, 35(6).

Figueiredo, M. V. B., Seldin, L., Araujo, F. F. de., \& Mariano, L. R. Plant growth promoting rhizobacteria: Fundamentals and applications. pp. 21-43. In: D. K. Maheshwari (ed.). Plant growth and health promoting bacteria. Springer-Verlag Berlin Heidelberg. 1821-43

Gitt, D. de C. Inoculação e coinoculação na cultura da soja. Boletim Técnico. Tecnologia de Produção de Soja. Fundação MS. n.1, 2014/2015. 18p.

Gitti, D. D. C., A. R. F., O., Portugal, J. R., Corsini, D. C. D. C., Rodrigues, R. A. F., \& Kaneko, F. H. Coberturas vegetais, doses de nitrogênio e inoculação de sementes com Azospirillum brasilense em arroz de terras altas no sistema plantio direto. Bragantia, 71, 509-517

Hungria, M., Campo, R. J., \& Mendes, I. C. Fixação biológica do nitrogênio na cultura da soja. Embrapa Soja: Circular Técnica. Londrina, BR. 48 p., 2001.

Kaschuk, G., Kuyper, T. W., Leffelaar, P. A., Hungria, M., \& Giller, K. E. Are the rates of photosynthesis stimulated by the carbon sink strength of rhizobial and arbuscular mycorrhizal symbioses? Soil Biology and Biochemistry, 41, 1233-1244

Kaschuk, G., Yin, X., Hungria, M., Leffelaar, P. A., Giller, K. E., \& Kuyper, T. W. Photosynthetic adaptation of soybean due to varying effectiveness of N 2 fixation by two distinct Bradyrhizobium japonicum strains. Environmental and Experimental Botany, 76, 1-6

Köppen, W., \& Geiger, R. Klimate der Erde. Gotha: Verlag Justus Perthes. 1928.

Kuss, A. V., Kuss, V. V., Lovato, T., \& Flôres, M. L. Fixação de nitrogênio e produção de ácido indolacético in vitro por bactérias diazotróficas endofíticas. Pesquisa Agropecuária Brasileira, 42, 1459-1465

Mandarino, J. M. G., \& Carrao-Panizzi. M. C. Programa de incentivo de utilização da soja na alimentação humana. Disponível em: Embrapa 2008.

Moraes, R. M. A. D., José, I. C., Ramos, F., Barros, E. G., \& Moreira, M. A. Caracterização bioquímica de linhagens de soja com alto teor de proteína. Pesquisa Agropecuária Brasileira, 41, 725- 
Naiman, A. D., Latrónico, A. E., \& García De Salamone, I. E. Inoculation of Wheat with Azospirillum brasilense and Pseudomonas fluorescens: impact on the production and rhizospheric microflora. European Journal of Soil Biology 45:44-51

Nogueira, M. A., Prando, A. M., Oliveira, A. B., Lima, A., Conte, O., Harger, N., Oliveira, F. T., \& Hungria, M. Ações de transferência de tecnologia em inoculação/coinoculação com Bradyrhizobium e Azospirillum na cultura da soja na safra 2017/18 no estado do Paraná. Embrapa Soja: Circular Técnica N. 143. Londrina, BR. 16 p., 2018.

Oliveira, M. A. Zucareli, C. Spolaor, L. T., Domingues, A. R., \& Ferreira, A. S. Desempenho agronômico do milho sob adubação mineral e inoculação das sementes com rizobactérias. Revista Brasileira de Engenharia Agrícola e Ambiental. [online]. 16, 1040-1046.

Perrig, D., Boiero, L., Masciarelli, O., Penna, C., Cassán, F., \& Luna, V. Plant growth promoting compounds produced byt wo agronomical lyimportant strains of Azospirillum brasilense, and their implications for inoculant formulation. Applied Microbiology and Biotechnology 75 , 1143- 1150

Plazinski, J., \& Rolfe, B. G. Influence of Azospirillum strains on the nodulation of clovers by Rhizobium strains. Appliedand Environmental Microbiology, 49, 984-989

Pommorsky, F. F. Desenvolvimento de pacote biotecnológico para tratamento de sementes de soja. Tese (Doutorado) - Universidade de São Paulo. Instituto de Ciências Biomédicas. Departamento de Microbiologia. 97 p.

Radwan, T. E. S. E. I. D., Mohamed, Z. K., \& Reis, V. M. Aeração e adição de sais na produção de ácido indolacético por bactérias diazotróficas. Pesquisa Agropecuária Brasileira, 40, 997-1004

Richardson, A. E. Prospects for using soil microorganisms to improve the acquisition of phosphorus by plants. Australian Journal Plant Physiology, 28: 897906, 2001.

Rodrigues, L. F. O. S., Guimarães, V. F., Silva, M. B., Junior, A. S. P., Klein, J., \& Costa, A. C. P. R. Características agronômicas do trigo em função de Azospirillum brasilense, ácidos húmicos e nitrogênio em casa de vegetação. Revista Brasileira de Engenharia Agrícola e Ambiental, $18,31-37$

Souchie, E. L., Azcón, R., Barea, J. M., Saggin-Júnior, O. J., \& Silva, E. M. R. Solubilização de fosfatos em meios sólido e líquido por bactérias e fungos do solo. Pesquisa Agropecuária Brasileira, 40, 1149-1152

Sousa, C. A., Lira-Junior, M. A., Freire, F. J., \& Sobral, J.K. Solubilização de fosfatos por bactérias endofíticas. In: XXXV Congresso Brasileiro de Ciência do Solo: O solo e suas múltiplas funções. 1-4.

Taiz, L., \& Zeiger, E. Fisiologia vegetal. Artemed, 2013.

Tartaglia, F. D. L., Carvalho, J. O. De, Ferreira, A., Melo, P. J. De, \& Toebe, M. Correlação linear de Pearson entre variáveis de soja. Revista Congrega Urcamp, 1, 1-2

Tedesco, M. J., Gianello, C., Bissani, C.A., Bohnen, H., \& Volkweiss, S. J. Análise de solo, plantas e outros materiais. (2a ed.), Departamento de Solos da Universidade Federal do Rio Grande do Sul. 1995. 174p. (Boletim Técnico de Solos, 5).

USDA. World agricultural supply and demand estimates. United States Department of Agriculture

Yokomizo, G. K., Duarte, J. B., \& Vella, N. A. Correlações fenotípicas entre tamanho de grãos e outros caracteres em topo cruzamentos de soja tipo alimento com tipo grão. Pesquisa Agropecuária Brasileira, .2235-2241

Zhang, F., Dashti, N., Hynes, R. K., \& Smith, D. Plant growth promoting rhizobacteria and soybean [Glycine max (L.) Merr.] nodulation and nitrogen fixation at suboptimal root zone temperatures. Annals of Botany, 77, 453-459 